OAK RIDGE

ORNL/TM-2011/95

NATIONAL LABORATORY

MANAGED BY UT-BATTELLE

FOR THE DEPARTMENT OF ENERGY

\title{
Cladding Alloys for Fluoride Salt Compatibility
}

May 25, 2011

Prepared by

Govindarajan Muralidharan

Dane F. Wilson

Larry R. Walker

Michael L. Santella

David E. Holcomb

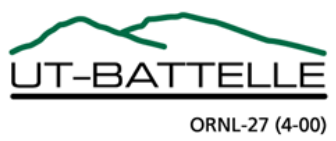




\section{DOCUMENT AVAILABILITY}

Reports produced after January 1, 1996, are generally available free via the U.S. Department of Energy (DOE) Information Bridge.

Web site http://www.osti.gov/bridge

Reports produced before January 1, 1996, may be purchased by members of the public from the following source.

National Technical Information Service

5285 Port Royal Road

Springfield, VA 22161

Telephone 703-605-6000 (1-800-553-6847)

TDD 703-487-4639

Fax 703-605-6900

E-mail info@ntis.gov

Web site http://www.ntis.gov/support/ordernowabout.htm

Reports are available to DOE employees, DOE contractors, Energy Technology Data Exchange (ETDE) representatives, and International Nuclear Information System (INIS) representatives from the following source.

Office of Scientific and Technical Information

P.O. Box 62

Oak Ridge, TN 37831

Telephone 865-576-8401

Fax 865-576-5728

E-mail reports@osti.gov

Web site http://www.osti.gov/contact.html

This report was prepared as an account of work sponsored by an agency of the United States Government. Neither the United States Government nor any agency thereof, nor any of their employees, makes any warranty, express or implied, or assumes any legal liability or responsibility for the accuracy, completeness, or usefulness of any information, apparatus, product, or process disclosed, or represents that its use would not infringe privately owned rights. Reference herein to any specific commercial product, process, or service by trade name, trademark, manufacturer, or otherwise, does not necessarily constitute or imply its endorsement, recommendation, or favoring by the United States Government or any agency thereof. The views and opinions of authors expressed herein do not necessarily state or reflect those of the United States Government or any agency thereof. 


\title{
CLADDING ALLOYS FOR FLUORIDE SALT COMPATIBILITY
}

\author{
Govindarajan Muralidharan \\ Dane F. Wilson \\ Larry R. Walker \\ Michael L. Santella \\ David E. Holcomb
}

Date Published: May 25, 2011

Prepared by OAK RIDGE NATIONAL LABORATORY

Oak Ridge, Tennessee 37831-6283

managed by

UT-BATTELLE, LLC

for the

U.S. DEPARTMENT OF ENERGY

under contract DE-AC05-00OR22725 



\section{CONTENTS}

\section{Page}

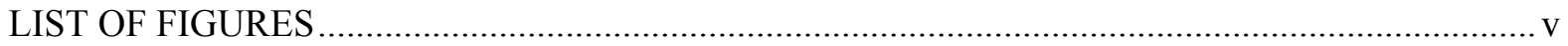

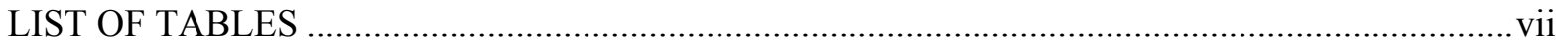

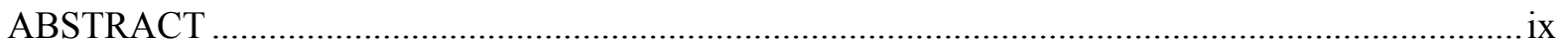

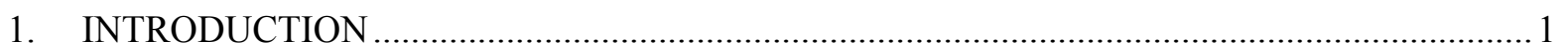

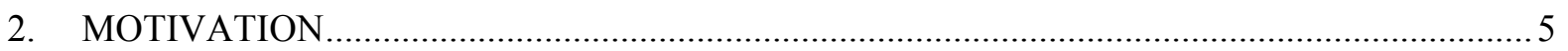

3. REQUIREMENTS OF CLADDING TECHNOLOGIES AND CLADDING

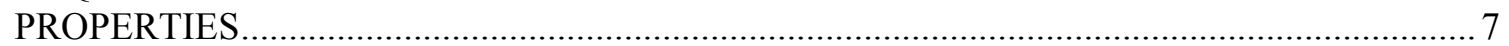

4. A BRIEF SURVEY OF RELEVANT CLADDING TECHNIQUES ..................................... 9

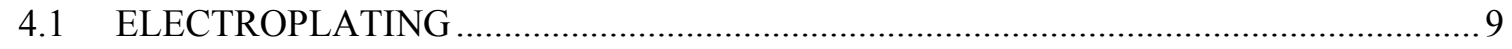

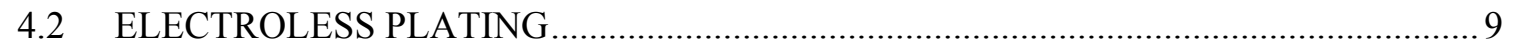

4.3 PHYSICAL VAPOR DEPOSITION-VACUUM EVAPORATION,

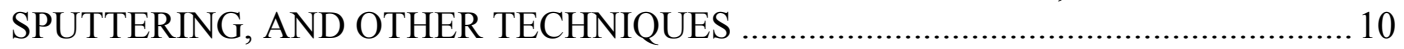

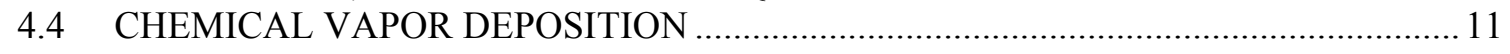

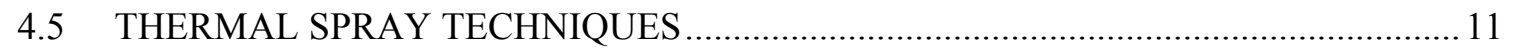

4.6 WELD OVERLAY, LASER CLADDING, AND RELATED TECHNIQUES ................ 12

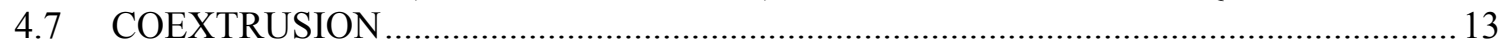

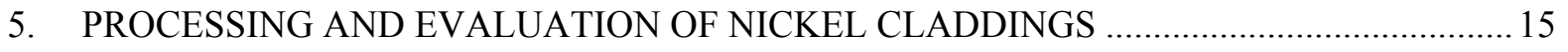

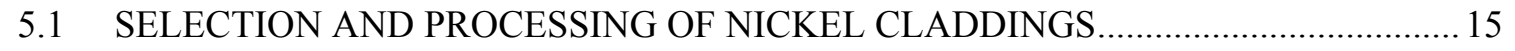

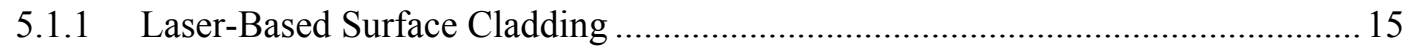

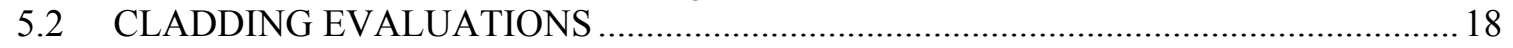

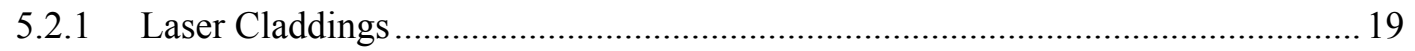

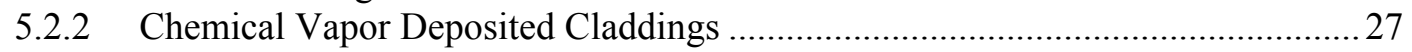

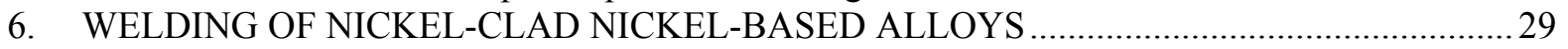

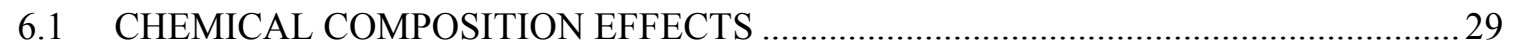

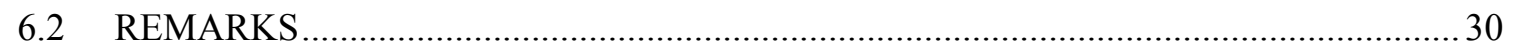

7. ON THE USE OF CLAD HIGH STRENGTH NI-BASED ALLOYS IN FHR ......................... 31

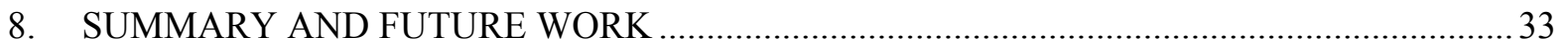

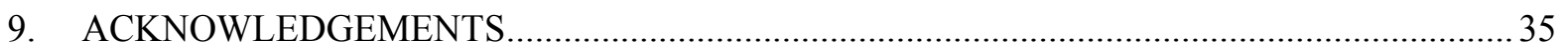

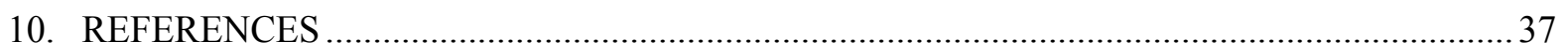





\section{LIST OF FIGURES}

FIG 1. INTERMEDIATE LIQUID SALT HEAT TRANSFER LOOP CONCEPTUAL DIAGRAM SHOWING THE SALT-SALT HEAT EXCHANGER AND THE SALT-GAS HEAT EXCHANGER. THE HEATED GAS CAN THEN BE TRANSPORTED FOR ELECTRICITY PRODUCTION USING THE BRAYTON CYCLE.

FIG 2. IMAGE OF THE LASER SETUP USED FOR LASER PROCESSING OF CLADDINGS...................16

FIG 3. OPTICAL IMAGE OF A NI-BASED ALLOY SUBSTRATE WITH A NI CLADDING APPLIED USING A LASER-BASED SURFACE CLADDING TECHNIQUE...................................................17

FIG 4. SCHEMATIC LAYOUT OF THE NI TETRACARBONYL DEPOSITION PROCESS. .......................18

FIG 5. OPTICAL IMAGE OF THREE NI-BASED SUBSTRATES COATED USING THE CVD NICKELCARBONYL PROCESS

FIG 6. (A) OPTICAL IMAGE OF THE NI CLADDING PROCESSED ON AN ALLOY 617 SUBSTRATE USING A LASER POWER OF 2500W. (B) CROSS-SECTIONAL OPTICAL MICROSCOPY OF SAMPLE SHOWN IN (A).

FIG 7. (A) OPTICAL IMAGE OF THE NI CLADDING PROCESSED ON AN ALLOY 617 SUBSTRATE USING A LASER POWER OF 3000W. (B) CROSS-SECTIONAL OPTICAL MICROSCOPY OF SAMPLE SHOWN IN (A).

FIG 8. (A) OPTICAL IMAGE OF THE NI CLADDING PROCESSED ON AN ALLOY 617 SUBSTRATE USING A LASER POWER OF 3500W. (B) CROSS-SECTIONAL OPTICAL MICROSCOPY OF SAMPLE SHOWN IN (A). .20

FIG 9. (A) OPTICAL IMAGE OF THE NI CLADDING PROCESSED ON AN ALLOY 617 SUBSTRATE USING A LASER POWER OF 4000W. (B) CROSS-SECTIONAL OPTICAL MICROSCOPY OF SAMPLE SHOWN IN (A).

FIG 10. (A) OPTICAL IMAGE OF THE NI CLADDING PROCESSED ON AN ALLOY 800H SUBSTRATE USING A LASER POWER OF 2500W. (B) CROSS-SECTIONAL OPTICAL MICROSCOPY OF SAMPLE SHOWN IN (A). 21

FIG 11. (A) OPTICAL IMAGE OF THE NI CLADDING PROCESSED ON AN ALLOY 800H SUBSTRATE USING A LASER POWER OF 3000W. (B) CROSS-SECTIONAL OPTICAL MICROSCOPY OF

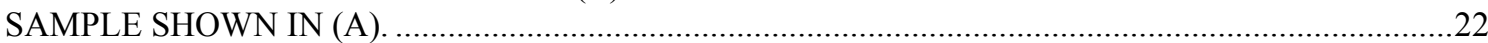

FIG 12. (A) OPTICAL IMAGE OF THE NI CLADDING PROCESSED ON AN ALLOY 800H SUBSTRATE USING A LASER POWER OF 3500W. (B) CROSS-SECTIONAL OPTICAL MICROSCOPY OF SAMPLE SHOWN IN (A). 22

FIG 13. (A) OPTICAL IMAGE OF THE NI CLADDING PROCESSED ON AN ALLOY 800H SUBSTRATE USING A LASER POWER OF 4000W. (B) CROSS-SECTIONAL OPTICAL MICROSCOPY OF SAMPLE SHOWN IN (A). 23

FIG 14. (A) CROSS-SECTIONAL OPTICAL MICROSCOPY OF NI CLADDING PROCESSED ON AN ALLOY 617 SUBSTRATE USING A LASER POWER OF 2500W. (B) MEASURED COMPOSITION PROFILE ALONG A LINE SHOWN IN 14 (A). THE COMPOSITION OF THE TOP SURFACE IS SHOWN ON THE RIGHT. 23

FIG 15. (A) CROSS-SECTIONAL OPTICAL MICROSCOPY OF NI CLADDING PROCESSED ON AN ALLOY 617 SUBSTRATE USING A LASER POWER OF 4000W. (B) MEASURED COMPOSITION PROFILE ALONG THE LINE SHOWN IN (A). THE COMPOSITION OF THE TOP SURFACE IS SHOWN ON THE RIGHT.

FIG 16. (A) CROSS-SECTIONAL OPTICAL MICROSCOPY OF NI CLADDING PROCESSED ON AN ALLOY 800H SUBSTRATE USING A LASER POWER OF 2500W. (B) MEASURED COMPOSITION PROFILE ALONG A LINE SHOWN IN (A). THE COMPOSITION OF THE TOP SURFACE IS SHOWN ON THE RIGHT.

FIG 17. (A) CROSS-SECTIONAL OPTICAL MICROSCOPY OF NI CLADDING PROCESSED ON AN ALLOY 800H SUBSTRATE USING A LASER POWER OF 4000W. (B) MEASURED COMPOSITION PROFILE ALONG A LINE SHOWN IN 16 (A). THE COMPOSITION OF THE TOP SURFACE IS SHOWN ON THE RIGHT.

FIG 18. (A) CROSS-SECTIONAL OPTICAL MICROSCOPY OF NI CLADDING PROCESSED ON AN ALLOY 617 SUBSTRATE USING A LASER POWER OF 4000W. (B) MEASURED 
MICROHARDNESS PROFILE ALONG A LINE SHOWN IN (A). LINE IS A VISUALIZATION AID.

FIG 19. (A) CROSS-SECTIONAL OPTICAL MICROSCOPY OF NI CLADDING PROCESSED ON AN ALLOY 800H SUBSTRATE USING A LASER POWER OF 4000W. (B) MEASURED MICROHARDNESS PROFILE ALONG A LINE SHOWN IN (A). LINE IS A VISUALIZATION AID.

FIG 20. (A) CROSS-SECTIONAL OPTICAL MICROSCOPY OF NI CLADDING PROCESSED ON AN ALLOY 800H SUBSTRATE (TEST 1). (B) CROSS-SECTIONAL OPTICAL MICROSCOPY OF NI CLADDING PROCESSED ON AN ALLOY 617 SUBSTRATE (TEST 2).

21. (A) CROSS-SECTIONAL OPTICAL MICROSCOPY OF NI CLADDING PROCESSED ON AN ALLOY 800H SUBSTRATE (TEST 1). (B) CROSS-SECTIONAL OPTICAL MICROSCOPY OF NI CLADDING PROCESSED ON AN ALLOY 617 SUBSTRATE (TEST 2).

FIG 22. (A) MEASURED MICROHARDNESS PROFILE WITHIN THE NI CLADDING AND 800H SUBSTRATE SHOWN IN FIGURE 20 (A). (B) MEASURED MICROHARDNESS PROFILE WITHIN THE NI CLADDING AND 617 SUBSTRATE SHOWN IN FIGURE 20 (B). 28

FIG 23. RELATIVE STABILITY OF FLUORIDES OF TYPICAL ELEMENTS IN HIGH STRENGTH NICKEL-BASED ALLOYS COMPARED TO THOSE OF FLUORIDES OF FLIBE, A SALT OF INTEREST. 


\section{LIST OF TABLES}

Table

Page

TABLE 1. PRIMARY ADVANTAGES AND DISADVANTAGES OF ELECTROPLATING. .9

TABLE 2. PRIMARY ADVANTAGES AND DISADVANTAGES OF ELECTROLESS PLATING.................9

TABLE 3. PRIMARY ADVANTAGES AND DISADVANTAGES OF VACUUM EVAPORATION .............10

TABLE 4. PRIMARY ADVANTAGES AND DISADVANTAGES OF SPUTTERING. .................................10

TABLE 5. PRIMARY ADVANTAGES AND DISADVANTAGES OF CHEMICAL VAPOR DEPOSITION.

TABLE 6. PRIMARY ADVANTAGES AND DISADVANTAGES OF THERMAL SPRAY TECHNIQUE. 12

TABLE 7. PRIMARY ADVANTAGES AND DISADVANTAGES OF WELD OVERLAY/LASER

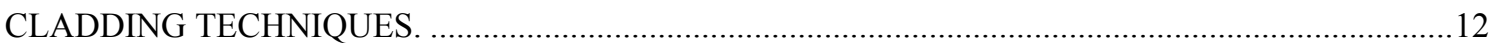

TABLE 8. PRIMARY ADVANTAGES AND DISADVANTAGES OF THE COEXTRUSION PROCESS....13

TABLE 9. SUMMARY OF PROCESSING CONDITIONS USED FOR LASER PROCESSING OF NI COATINGS ON NICKEL BASED ALLOY SUBSTRATES. . .16

TABLE 10. NOMINAL COMPOSITIONS OF ALLOY SUBSTRATES USED IN THE STUDY...................16

TABLE 11. EFFECTS OF SOME COMMONLY PRESENT ELEMENTS ON THE WELDABILITY OF NICKEL ALLOYS. 



\begin{abstract}
Heat transport systems are essential components in fluoride-salt-cooled reactors. Conceptually, the heat transport system of a fluoride-salt-cooled high-temperature reactor (FHR) consists of two interconnected salt loops. The primary loop contains the reactor core and is heated by the nuclear fission process. The intermediate loop transfers heat from the primary loop to a secondary, electricity generation loop. Choice of materials is critical to achieving the functionality, reliability, and targeted lifetime of FHR structures. Even at high temperatures, nickel-based alloys embrittle under neutron radiation. Hence nickel-based alloys are being considered only for FHR structures (including heat exchangers and pumps) that are located outside the core. In those applications, the structural alloy requires both mechanical strength (yield strength and creep strength) and corrosion resistance to fluoride salts, air, and the power cycle working fluid.
\end{abstract}

The functional requirements for the structural alloy can logically be separated into mechanical and chemical requirements. The U.S. Department of Energy has been sponsoring work through its hightemperature gas reactor (HTGR) program on qualifying select high-nickel alloys (Alloy $800 \mathrm{H}$, Inconel 617, and Haynes 230) for high-temperature nuclear service. However, none of these alloys are chemically compatible with hot fluoride salts due to additions of substantial amounts of alloying elements that are susceptible to dissolution in liquid fluorides. While a single material with the required high-temperature strength and chemical compatibility with the fluoride salts would be ideal for this application, cladding a structural alloy to provide corrosion resistance to an otherwise chemically incompatible high-strength material is a commonly used technique in the nuclear power industry and is another viable option.

This report identifies the key property requirements of the claddings that would be required for long term service in contact with liquid salt at high temperatures. It provides an overview of several candidate cladding technologies that could potentially be used for cladding nickel-based corrosion protection layers onto high-temperature structural alloys. From the available techniques, two cladding technologies were selected for initial evaluation. The first technique was a line-of-sight method that would be useful for cladding large structures such as vessel interiors or large piping. The line-of-sight method used was a laser-based surface cladding technique in which a high-purity nickel powder mixed into a polymer binder was first sprayed onto the surface, baked, and then rapidly melted using a high-power laser. The second technique was a non-line-of-sight cladding technique- a vapor phase technique based on the nickel-carbonyl process that is suitable for cladding inaccessible surfaces such as the interior surfaces of heat exchangers.

Nickel claddings were prepared on Alloy 617 and Alloy $800 \mathrm{H}$ substrates using the laser-based cladding process and the nickel-carbonyl based Metal Organic Chemical Vapor Deposition (MOCVD) process. In general, the quality of laser-based claddings was acceptable with occasional presence of few voids, pinholes, and cracks. These were regions in which the coatings had spalled; it is anticipated that optimization of the process would eliminate these spalled regions. In addition, good adhesion along with good mixing was present at the interface between the cladding and the substrate. A portion of the substrate from the near-surface region was observed to have melted and intermixed with the cladding material with the size of this region increased laser power. Alloying elements from the substrate were identified within the cladding layer with their concentration increasing with increase in laser power. In general, the composition gradients were less prominent when the laser claddings were processed at larger powers. Results from microhardness tests on the cladding and the near-substrate region in the matrix show that the cladding layer was softer than the matrix. It was concluded that the laser processing could be successfully used to modify the surface composition of 
Alloy 617 and Alloy $800 \mathrm{H}$ with a nickel cladding layer through an appropriate selection of process parameters.

Relatively thick claddings were processed using the MOCVD process. These claddings were of good quality with no pinholes or cracks. In contrast to the laser-based cladding process, sharp interfaces were observed between the cladding and substrate with little or no intermixing. Hence the composition of the nickel cladding layers was essentially pure nickel with little or no matrix elements present within the cladding layer. An intermediate oxide layer was found to be present between the substrate and cladding layers due to initial oxidation of the substrate and could potentially affect the adhesion and interdiffusion between the substrate and the cladding. It was concluded that the MOCVD process could be used for nickel cladding if appropriate substrate cleaning techniques could be developed to improve the adhesion of coatings.

A cursory literature review indicates there is very little published information about welding or weld performance issues related to welding of nickel-coated nickel-based alloys. Based on a general understanding of welding, one can imagine there are two types of concerns for this situation. The first is the effect of incorporating any nickel cladding into a weld deposit made in a nickel-based alloy or into base metal heat-affected zones. The second type of concern is whether nickel cladding integrity can be maintained after welding operations. These issues have to be addressed to understand the fabricability of FHR components using clad nickel-based alloys.

In conclusion, the feasibility of cladding nickel-based alloys with nickel-rich surface layers was demonstrated. Process optimization and evaluation of liquid salt resistance of claddings are essential to understand the effect of cladding characteristics on the salt resistance and in particular, the long term performance characteristics. 


\section{INTRODUCTION}

Heat transport systems are essential components in fluoride-salt-cooled reactors. Conceptually, the heat transport system of a fluoride-salt-cooled high-temperature reactor (FHR) consists of two interconnected loops. The primary loop contains the reactor core and is heated by the nuclear fission process. The intermediate loop transfers heat from the primary loop to a secondary, electricity generation loop. The primary loop's fluoride salt must be both compatible with intense neutron irradiation and an effective heat transfer medium. A review of the selection criteria for primary loop salts was performed in 2006, ${ }^{1}$ and an analysis of the component testing requirements has recently been published. ${ }^{2}$ The recent report includes an overview of the major plant components.

In addition to its heat transport function, the intermediate loop serves as a buffer to prevent fuel leakage and/or induced radioactivity in the primary loop from exiting containment and isolates the low-pressure primary system from the high-pressure electricity generation cycle. FHRs also have a direct reactor auxiliary cooling system (DRACS), a core decay heat removal loop that transfers heat via natural convection from the primary coolant to ambient air. The DRACS concept was originally developed for the Experimental Breeder Reactor II and has been used in a number of reactor designs. ${ }^{3}$ Thermal energy is transferred first from the primary coolant into the DRACS via an in-vessel natural circulation loop and then to an external cooling loop via a natural draft heat exchanger.

The physical configuration of the primary loop varies depending on whether the heat exchanger to the intermediate loop is located within the primary reactor vessel. When the heat exchanger is integral to the reactor vessel, no external piping is used and a centrifugal pump drives the fluid flow through the primary loop. The primary-to-intermediate heat exchanger is most likely a shell-and-tube type due to the technological maturity of that type of heat exchanger and the excellent heat transfer properties of liquid fluoride salts.

The intermediate heat transfer loop (shown conceptually in Fig 1) also uses a fluoride salt as the heat transfer medium. A description and evaluation of liquid salt heat transport technology has also recently been published. ${ }^{4}$ The intermediate heat transfer loop, containing a single-phase, incompressible liquid, requires a void space to accommodate the expansion of the salt and a drain tank to allow for servicing. Because the fluoride salts have melting points well above ambient temperature, loop preheating is also required during filling of the system. Control of the chemistry and purification of the salt is necessary in order to maintain the structural integrity of the material surfaces that are wetted by the salt. In addition, because a liquid salt heat transfer loop separates the liquid salt from a gas (with the gas at high pressures), sufficient physical loop length and pressure relief mechanisms are required to prevent a severe accident (i.e., to prevent a blast wave from propagating upstream to the reactor from the downstream conversion process for power generation or chemical processes).

Choice of materials is critical to achieving the functionality, reliability, and targeted lifetime of FHR structures. Even at high temperatures, nickel-based alloys embrittle under neutron radiation. Hence nickel-based alloys are being considered only for FHR structures (including heat exchangers and pumps) that are located outside the core. In those applications, the structural alloy requires both mechanical strength (yield strength and creep strength) and corrosion resistance to fluoride salts, air, and the power cycle working fluid. Also, the structural alloy needs to be reasonably formable and joinable and not prohibitively expensive. In addition, the alloy needs to have the extensive pedigree required for incorporation into the high-temperature nuclear section of the AMSE Boiler and Pressure Vessel Code. 


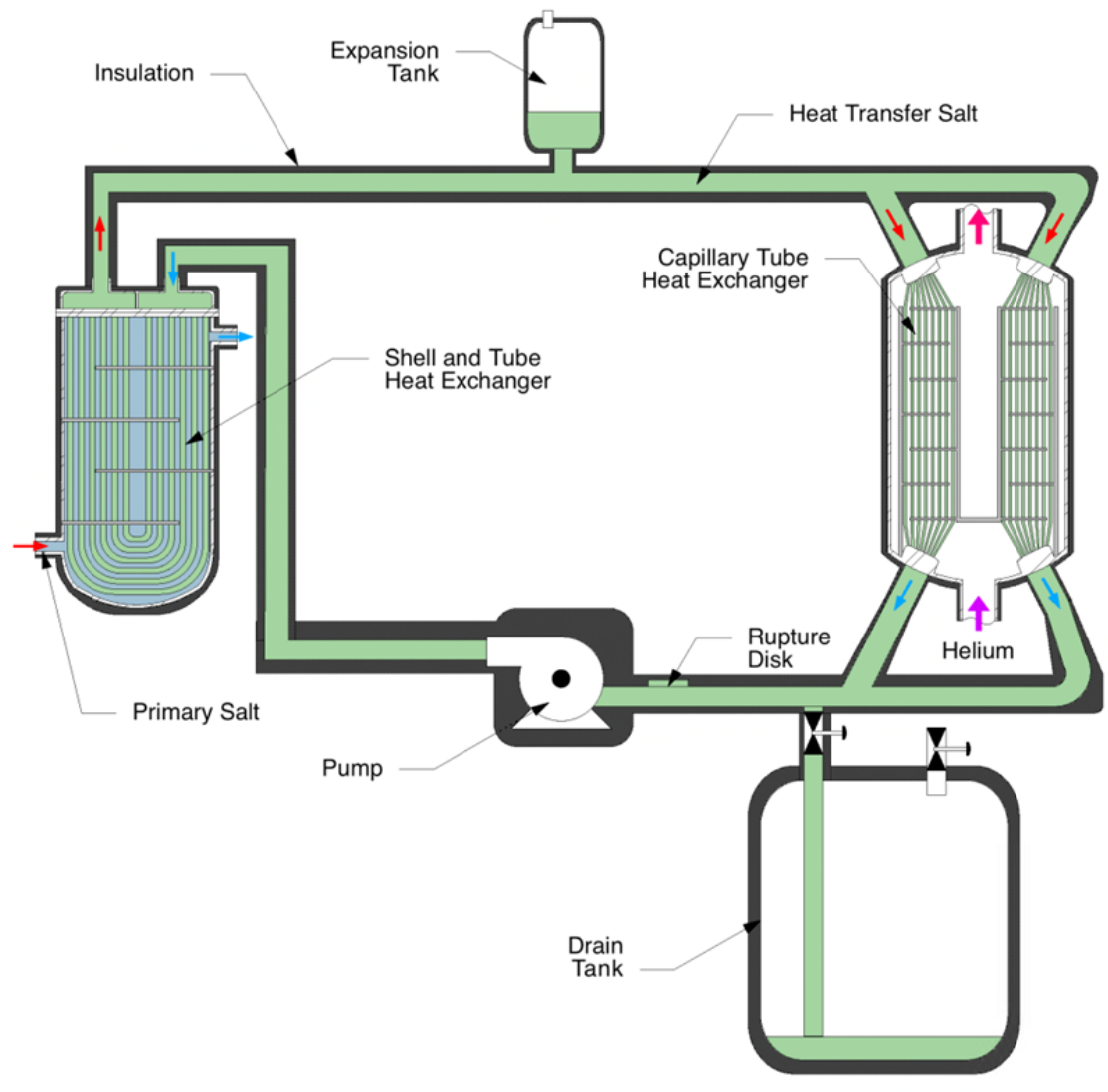

Fig 1. Intermediate liquid salt heat transfer loop conceptual diagram showing the salt-salt heat exchanger and the salt-gas heat exchanger. The heated gas can then be transported for electricity production using the Brayton cycle.

The functional requirements for the structural alloy can logically be separated into mechanical and chemical requirements. The U.S. Department of Energy has been sponsoring work through its hightemperature gas reactor (HTGR) program on qualifying select high-nickel alloys (Alloy $800 \mathrm{H}$, Inconel 617, and Haynes 230) for high-temperature nuclear service. However, none of these alloys is chemically compatible with hot fluoride salts due to additions of substantial amounts of alloying elements that are susceptible to dissolution in liquid fluorides. ${ }^{5}$ While a single material with the required high-temperature strength and chemical compatibility with the fluoride salts would be ideal for this application, cladding a structural alloy to provide corrosion resistance to an otherwise chemically incompatible high-strength material is a commonly used technique in the nuclear power industry and is another viable option. For example, pressurized-water reactors are constructed from carbon or low-alloy steels and are lined with a stainless steel to impart chemical compatibility with the borated primary coolant water.

HTGR structural alloys have similar mechanical performance requirements as those for an FHR. The most challenging mechanical requirements for an alloy are in the salt-to-gas heat exchanger used to couple an FHR to an electricity-generating cycle. An FHR can couple to any high-temperature power generation cycle; possible high-temperature working fluids include carbon dioxide, steam, air, helium, and helium-nitrogen. A common feature of FHRs is that the working fluids operate at high pressure. The requirement to efficiently transfer heat from a low-pressure fluoride salt to a highpressure working fluid for many years creates significant constraints on the mechanical properties for the structural alloy. FHRs employ a primary fluoride salt loop heated by the nuclear reactor core, an intermediate fluoride salt loop that isolates the primary system, and either a secondary electricity 
generation loop or a chemical process cycle. Hence, the separation provided by the intermediate loop avoids having the secondary heat exchanger serve a primary coolant containment function, thereby reducing somewhat its material qualification requirements. The secondary heat exchanger structural alloy options are therefore more numerous than those for the primary vessel, heat exchanger, and piping.

Fluoride salts are effective fluxes for metal oxides and hence chromia or alumina scales, which provide high-temperature oxidation resistance, are ineffective against fluoride salt corrosion. Therefore, the cladding layer must rely upon intrinsic thermochemical stability and very slow interdiffusion rates to provide corrosion resistance. Among the fluorides of elemental additions to common structural alloys, nickel fluoride is less stable than the fluorides of other alloying elements and, more importantly, is less stable than the components of the proposed coolant fluoride coolant salt. Thus, nickel is less vulnerable to dissolution into a fluoride salt. In practice, because nickel is known to be chemically compatible with fluoride salts at high temperatures, nickel-based materials are leading candidates to serve as the cladding layer.

The objective of the current project is to evaluate the feasibility of using a nickel-based cladding as a corrosion-resistant layer on a substrate structural alloy that is suitable for use as a fluoride salt containment material outside the reactor core of an FHR. Using Inconel ${ }^{\circledR} 617$ and Alloy $800 \mathrm{H}$ as example substrates, the effectiveness of a range of cladding techniques to process nickel claddings is being evaluated. In addition, joining techniques for the clad material systems that would be appropriate for forming complex structures (e.g., heat exchangers) are being examined.

Fabrication of test material coupons, physical evaluation of the quality of the claddings, and initial examination of potential joining techniques for the clad materials have been performed. This report describes and evaluates candidate cladding approaches and reports on the results of the cladding performance. 



\section{MOTIVATION}

Nuclear power plants are large, complex, expensive, and highly regulated structures intended to operate with high availability for up to a century. Failure of a plant's primary coolant boundary will likely have large safety consequences or at a minimum, will grossly impact the plant functionality and economic performance. High confidence is therefore required in any structural material or fabrication technique before it can be put into practice in a nuclear power plant.

A primary motivation for this cladding evaluation project is thus to begin to develop the evidence necessary to establish confidence in nickel-based cladding as an appropriate means of providing corrosion protection to an FHR's salt-contacting structural alloys. The high-temperature interaction between the cladding layer and the structural alloy may prevent either from performing its function. This project also seeks to acquire the information necessary to enable a more fundamental understanding of the functioning of nickel-based cladding as a corrosion prevention layer on FHR structural alloys as well as the high-temperature interaction of the cladding layer with the structural alloy. Understanding the cladding and structural alloy performance and evolution with time and temperature will enable establishing observable metrics of adequate cladding application and optimizing the cladding structure, composition, and application technique.

Another project motivation is to learn whether any technological barriers prevent the practical application of functional nickel-based cladding layers to high-nickel structural alloys. The chemical, mechanical, and microstructural characteristics of the cladding layers can be different for each of the different techniques, and techniques that are ideally suited for cladding the interior surfaces of smalldiameter piping may not provide composite characteristics that are functionally important. 



\section{REQUIREMENTS OF CLADDING TECHNOLOGIES AND CLADDING PROPERTIES}

A number of cladding properties are critical for successful utilization of claddings in various components of FHRs:

- The composition of claddings should consist of elements that have low solubility in the liquid salt. Mixing between substrate and claddings, if present, should still allow control of composition near the surface to desired ranges.

- Composition of claddings must be stable during long-term exposure at high temperatures at which interdiffusion is predominant

- Claddings should be free of pinholes, voids, surface cracks, and significant internal cracks.

- Claddings must have excellent adhesion to the substrate.

- Claddings must have reasonable uniformity in thickness to enable conformation to engineering design specifications.

- Mechanical properties of claddings are critical for the application-Claddings should have appropriate hardness and wear resistance while showing sufficient ductility and resistance to cracking.

- The thermal expansion coefficients of claddings must be reasonably close to that of the substrate to minimize thermal stresses and to maximize thermal fatigue resistance.

Many of the characteristics of claddings are determined by the technique used for their processing. A number of techniques can be utilized for cladding nickel-based alloys with metallic nickel, resulting in composite materials with different characteristics. Important characteristics of the processes include the following:

- Substrate temperature and temperature of cladding material: The substrate temperature has a significant effect on the microstructure and the properties of the composite material. In some processes, the cladding precursor may be directly melted onto the substrate surface; in other processes, the cladding may be deposited on a cold or warm substrate surface from the vapor phase.

- Area of deposition and rate of deposition: The technique should have a reasonable rate of deposition and the ability to cover large surface areas within a reasonable time and should be able to be scaled up for manufacturing.

- Surface accessibility and deposition: Certain techniques are applicable primarily to line-of-sight surfaces while other techniques may be applicable for cladding complex shapes and surfaces with no line-of-sight access.

Characteristics of the cladding techniques impact their applicability. For example, a directionally applied technique such as welding would be impractical on the interior surfaces of heat exchanger tubing. Similarly, coextrusion techniques cannot be applied following component fabrication. Additionally, the quality of the cladding layer may depend strongly on both the application technique and the application parameters. Some cladding application techniques are prone to producing pinholes or to depositing layers that do not adhere strongly to the substrate. Some application techniques may be impractical even though they deposit a high-quality cladding layer-some chemical vapor deposition (CVD) techniques only deposit material at submicron-per-hour rates.

The most appropriate cladding technique will likely be chosen to suit the physical configuration of the FHR structures. Some salt-wetted surfaces in FHRs will be complex and inaccessible. It is particularly challenging to gain access to the interior of long capillary tubing, both to apply a cladding and to verify that the cladding has been properly applied. Similarly, the sharp edges of a pump impeller will alter the local material deposition rate of electrochemically driven deposition 
techniques. Overall, a wide range of nickel-based cladding deposition techniques is available. This project seeks to evaluate the merits and difficulties of the most relevant cladding technologies. 


\section{A BRIEF SURVEY OF RELEVANT CLADDING TECHNIQUES}

The following is a brief survey of cladding techniques and their relative advantages and disadvantages that were considered to be relevant to the cladding of nickel alloys on nickel-based alloy substrates. This survey is not meant to be exhaustive but illustrates the issues that were considered in the evaluation of a myriad of cladding techniques that could be employed to apply nickel claddings. The advantages and disadvantages of each of these techniques were considered in selecting two processes that would be used for preparing representative materials for evaluation.

\subsection{ELECTROPLATING}

Nickel can be electrodeposited from a conductive aqueous solution of nickel salts with the material to be plated being the cathode (see Table 1). Electrodeposited claddings for engineering applications may be prepared from two most popular solutions-Watts and nickel sulfamate baths. ${ }^{6}$

Table 1. Primary advantages and disadvantages of electroplating.

\begin{tabular}{lll}
\hline \multicolumn{1}{c}{ Advantages } & \multicolumn{1}{c}{ Disadvantages } \\
\hline - Relatively well-understood and well- & - & Limited capability to clad non-line-of-sight surfaces \\
characterized process & - Large parts may be difficult to clad due to electrolyte \\
- Widely accepted in industrial & tank size limitations \\
processing & - Complex parts may be difficult to clad \\
- Relatively inexpensive & - Uniformity of claddings depends on current distribution \\
& and hence part geometry \\
& - Environmental issues related to plating solutions \\
\hline
\end{tabular}

Sources:

G. A. Di Bari, "Nickel Plating," in ASM Handbook (ASM International, 1994), 5: 201-212.

T. Mooney, "Electroplated Coatings," in ASM Handbook (ASM International, 2003), 13A: 772-785.

\subsection{ELECTROLESS PLATING}

In contrast to electroplating, electroless nickel plating is used to deposit nickel without the use of an electric current (see Table 2). The cladding is deposited by an autocatalytic chemical reduction of nickel ions by hypophosphite, aminoborane, or borohydride compounds. ${ }^{8}$

Table 2. Primary advantages and disadvantages of electroless plating.

\begin{tabular}{lll}
\hline \multicolumn{2}{c}{ Advantages } & \multicolumn{1}{c}{ Disadvantages } \\
\hline - Good resistance to corrosion and wear & - & Brittleness \\
- Excellent uniformity & Poor welding characteristics due to \\
- Ability to be soldered and brazed & & $\begin{array}{l}\text { contamination of nickel cladding with nickel } \\
\text { phosphorus deposits }\end{array}$ \\
- Relatively well-understood and well- & & Presence of phosphorus not desirable for \\
characterized process & nuclear applications \\
- Widely accepted in industrial & - Need to copper-strike-plate alloys before \\
processing & & electroless nickel can be applied \\
- Simple process and low labor costs & - Slower plating rate than electrolytic methods \\
& - Higher chemical cost than electroplating \\
\hline
\end{tabular}

Source: D. W. Baudrand, "Electroless Nickel Plating," in ASM Handbook (ASM

International, 1994), 5: 290-310. 


\subsection{PHYSICAL VAPOR DEPOSITION—VACUUM EVAPORATION, SPUTTERING, AND OTHER TECHNIQUES}

Vapor-based processes that can be used for cladding include the physical vapor deposition (PVD) techniques, such as vacuum evaporation, sputtering, ion plating, ion-beam assisted deposition, arc deposition, and ion implantation. In the vacuum evaporation process, deposition is achieved from the vapor phase containing the required atoms, typically provided by a vaporization source (see Table 3 ). Deposition of high-purity films requires appropriate control of vacuum levels. ${ }^{9}$

Table 3. Primary advantages and disadvantages of vacuum evaporation.

\begin{tabular}{|c|c|}
\hline Advantages & Disadvantages \\
\hline $\begin{array}{l}\text { - High-purity films can be deposited over } \\
\text { large areas at a reasonable rate } \\
\text { - Deposition can be carried out at low } \\
\text { substrate temperature and hence minimizes } \\
\text { issues with substrate microstructure and } \\
\text { property modification due to the cladding } \\
\text { process } \\
\text { - Process can be scaled using large sources } \\
\text { - Relatively inexpensive compared with } \\
\text { other PVD techniques }\end{array}$ & $\begin{array}{l}\text { - Film properties are poor and have the potential for } \\
\text { flaws (e.g., pinholes, porosity, residual stresses) } \\
\text { - Lack of process control to improve film properties } \\
\text { - High vacuum levels are required to obtain films of } \\
\text { good quality } \\
\text { - A line-of-sight process and may not be suitable for } \\
\text { narrow diameter tubes } \\
\text { - Substrate surface preparation may be critical in } \\
\text { determining adhesion and properties } \\
\text { - Difficult to achieve uniformity of film thickness over } \\
\text { large areas } \\
\text { - Higher capital costs when compared with other } \\
\text { techniques such as electroplating }\end{array}$ \\
\hline
\end{tabular}

Source: D. M. Mattox, "Vacuum Deposition, Reactive Evaporation, and Gas Evaporation," in ASM Handbook (ASM International, 1994), 5: 556-572.

Sputtering is a nonthermal vaporization process in which surface atoms from a source are physically ejected by transfer of momentum from an energetic bombarding species of atomic/molecular size. Typically, sputtering uses a glow discharge or an ion beam to generate a flux of ions incident on the target surface. The ions cause atoms and, in some cases, clusters of atoms to be knocked free from the target surface by impact transfer, or sputtering. Redeposition of the sputtered atoms onto another surface or substrate results in sputter deposition of cladding. Compared with other thin-film deposition methods, sputter deposition techniques have several distinct advantages (see Table 4). ${ }^{9-11}$

Table 4. Primary advantages and disadvantages of sputtering.

\begin{tabular}{|c|c|}
\hline Advantages & Disadvantages \\
\hline $\begin{array}{l}\text { - Deposition can be carried out at low substrate } \\
\text { temperature and hence minimizes issues with } \\
\text { substrate microstructure and property } \\
\text { modification due to the cladding process } \\
\text { - Uniformity of film thickness over large } \\
\text { areas } \\
\text { - Good film adhesion } \\
\text { - Well accepted industrially scalable, } \\
\text { environmentally friendly process }\end{array}$ & $\begin{array}{l}\text { - Slow deposition rates (typically less than } 300 \mathrm{~nm} / \mathrm{min} \text { ) } \\
\text { - A line-of-sight process and may not be suitable for } \\
\text { narrow-diameter tubes or excessively large } \\
\text { components } \\
\text { - Substrate surface preparation may be critical in } \\
\text { determining adhesion and properties } \\
\text { - Setup costs are high because of vacuum and energy } \\
\text { efficiency is low ( } 70 \% \text { or more of the input energy is } \\
\text { expended in target heating). }\end{array}$ \\
\hline
\end{tabular}

Sources:

D. M. Mattox, "Vacuum Deposition, Reactive Evaporation, and Gas Evaporation," in ASM Handbook (ASM International, 1994), 5: 556-572.

"CVD and PVD Coatings," in ASM Handbook (ASM International, 2003), 13A: 759-762.

S. L. Rohde, "Sputter Deposition," in ASM Handbook (ASM International, 1994), 5: 573-581. 


\subsection{CHEMICAL VAPOR DEPOSITION}

The CVD process can be defined as the deposition of a solid on a heated surface via a chemical reaction from the vapor or gas phase. The decomposition of nickel carbonyl is the most frequently used reaction to deposit nickel from the vapor phase: ${ }^{12}$

$$
\mathrm{Ni}(\mathrm{CO})_{4} \rightarrow \mathrm{Ni}+4 \mathrm{CO}
$$

The reaction temperature ranges from 180 to $200^{\circ} \mathrm{C}\left(355\right.$ to $\left.390^{\circ} \mathrm{F}\right)$, and the pressure can be as high as ambient. The ductility of the deposited nickel is dependent on the deposition rate. The primary advantages and disadvantages of the CVD process are summarized in Table 5.

Table 5. Primary advantages and disadvantages of chemical vapor deposition.

\begin{tabular}{|c|c|}
\hline Advantages & Disadvantages \\
\hline $\begin{array}{l}\text { Deposition can be carried out at temperatures much } \\
\text { lower than the melting temperature of the material } \\
\text { being deposited and hence minimizes issues with } \\
\text { substrate microstructure and property modification } \\
\text { due to the cladding process } \\
\text { - Microstructural characteristics such as grain } \\
\text { orientation and grain size can be controlled through } \\
\text { process parameters } \\
\text { - Relatively simple equipment } \\
\text { - Adaptable } \\
\text { - Economically competitive } \\
\text { - Ambient pressure processing possible } \\
\text { - Relatively high deposition rate and thicker claddings } \\
\text { can be obtained } \\
\text { - Good bonding is generally achieved if surface } \\
\text { preparation is appropriate } \\
\text { Non-line-of-sight deposition along with the ability } \\
\text { to coat deep recesses and high-aspect-ratio holes }\end{array}$ & $\begin{array}{l}\text { - Chemical precursors are hazardous or } \\
\text { extremely toxic, which necessitates a } \\
\text { closed system } \\
\text { - By-products may be toxic and corrosive } \\
\text { and have to be disposed of appropriately } \\
\text { - Energy requirements can be high, } \\
\text { especially when high deposition } \\
\text { temperatures are required } \\
\text { - Low-efficiency of the process, resulting in } \\
\text { high costs }\end{array}$ \\
\hline
\end{tabular}

\subsection{THERMAL SPRAY TECHNIQUES}

In the thermal spray process, cladding material in the form of powder, wire, or rod is fed into a torch or a gun, where it is heated to near or above its melting point. ${ }^{13}$ A stream of gas propels the resulting molten or nearly molten droplets of material toward the substrate. On impact, the droplets are mechanically deformed and adhere to the surface while overlapping and interlocking during the process of solidification. The total cladding thickness is usually generated in multiple passes of the cladding device (see Table 6). 
Table 6. Primary advantages and disadvantages of thermal spray technique.

\begin{tabular}{|c|c|}
\hline Advantages & Disadvantages \\
\hline $\begin{array}{l}\text { - Deposition can be carried out without } \\
\text { significant heating of the substrate hence } \\
\text { minimizes issues with substrate microstructure } \\
\text { and property modification due to the cladding } \\
\text { process } \\
\text { - Ability to coat large areas at reasonable rates } \\
\text { - Complex parts can be coated }\end{array}$ & $\begin{array}{l}\text { - A line-of-sight process and may not be suitable for } \\
\text { narrow-diameter tubes and deep cavities } \\
\text { - Surface finish and composition of cladding have to } \\
\text { be monitored and controlled } \\
\text { - Substrate surface preparation may be critical in } \\
\text { determining adhesion and properties. } \\
\text { - Multiple passes may be required for relatively } \\
\text { thick claddings } \\
\text { - Depending on the technique used, claddings may } \\
\text { have some porosity and may have low density }\end{array}$ \\
\hline
\end{tabular}

Source: R. C. Tucker, Jr, "Thermal Spray Coatings," in ASM Handbook (ASM International, 1994), 5: 497_509.

\subsection{WELD OVERLAY, LASER CLADDING, AND RELATED TECHNIQUES}

In the weld-overlay/laser-cladding class of techniques, a source of heat is used to accomplish heating and melting of the cladding material on top of the substrate to be cladded. ${ }^{14}$ The heat source can be a welding torch, such as the torch used in the gas tungsten arc-welding process, or from a laser (see Table 7). A certain amount of the substrate is also melted during the process, resulting in dilution of the cladding layer (the amount of dilution depends on the amount of heat supplied).

Table 7. Primary advantages and disadvantages of weld overlay/laser cladding techniques.

\begin{tabular}{|c|c|}
\hline Advantages & Disadvantages \\
\hline $\begin{array}{l}\text { - Good adhesion with substrate due to intimate } \\
\text { mixing at the substrate-cladding interface } \\
\text { - Limited capability to coat non-line-of-sight } \\
\text { surfaces } \\
\text { - Ability to coat large areas at reasonable rates by } \\
\text { rastering } \\
\text { - Thick claddings may be achievable in a single } \\
\text { pass } \\
\text { - Surface preparation may be less critical since } \\
\text { high temperatures are involved }\end{array}$ & $\begin{array}{l}\text { - Typically a line-of-sight process and not suitable } \\
\text { for cladding narrow-diameter tubes or deep } \\
\text { cavities } \\
\text { - Surface region is melted and resolidified, } \\
\text { resulting in microstructural and property } \\
\text { modifications of substrate region close to the } \\
\text { surface } \\
\text { - Mixing between substrate surface and cladding } \\
\text { can result in modification of cladding } \\
\text { composition } \\
\text { - Since high surface temperatures are involved, a } \\
\text { heat-affected zone exists underneath the surface } \\
\text { layer, resulting in microstructure and property } \\
\text { modifications of the substrate } \\
\text { - Process parameters are critical in determining } \\
\text { properties because they determine heating and } \\
\text { cooling and hence cladding and near-surface } \\
\text { substrate properties }\end{array}$ \\
\hline
\end{tabular}

Source: K. P. Cooper, "Laser Surface Processing," in ASM Handbook (ASM International, 1992), 18: 861-872. 


\subsection{COEXTRUSION}

Coextrusion is the process of simultaneous extrusion of materials to form a bimetallic composite (see Table 8). In the coextrusion process, a core material is extruded along with the clad material through a convergent die. The concurrent deformation of the core and the clad material results in the formation of an interfacial bonding layer between the core and the cladding. The coextrusion or codrawing process can be carried out at appropriate temperatures for the system of materials under consideration and can be accomplished using conventional extrusion or drawing equipment. Other variations, such as friction extrusion or hydrostatic extrusion, are also possible. The coextrusion process is typically carried out using materials with widely different mechanical properties - either hard core/soft clad or soft core/hard clad. Hence, successful coextrusion depends on a number of factors, such as metallurgical and mechanical compatibility of the two materials and a number of process parameters that influence the flow behavior of the two materials. ${ }^{15}$

Table 8. Primary advantages and disadvantages of the coextrusion process.

\begin{tabular}{lll}
\hline \multicolumn{1}{c}{ Advantages } & \multicolumn{1}{c}{ Disadvantages } \\
\hline - $\begin{array}{l}\text { Equipment is relatively simple; conventional } \\
\text { metal-working equipment may be adequate }\end{array}$ & $\bullet \begin{array}{l}\text { Generalized process recipe not available; significant } \\
\text { investment in process development is needed }\end{array}$ \\
- $\begin{array}{l}\text { Long lengths of materials can be processed } \\
\text { fairly efficiently; high throughput can be } \\
\text { achieved }\end{array}$ & $\begin{array}{l}\text { Customized process requires new process } \\
\text { development if material combinations/properties are } \\
\text { changed }\end{array}$ \\
$\begin{array}{l}\text { Cladding of internal surfaces possible using } \\
\text { nickel as the internal clad layer followed by } \\
\text { piercing to form hollow tube }\end{array}$ & $\bullet \begin{array}{l}\text { Surface cleanliness may be critical for good } \\
\text { adhesion }\end{array}$ \\
& $\bullet \begin{array}{l}\text { May be more suitable for fabrication of tubes than } \\
\text { for other bulk components }\end{array}$ \\
& $\bullet \begin{array}{l}\text { Can be primarily used for initial fabrication of } \\
\text { components but not for field fabrication or for repair }\end{array}$ \\
\hline
\end{tabular}

Source: R. Srinivasan and C. S. Hartley, "Coextrusion," in ASM Handbook (ASM International, 2005), 14A: 505-515. 



\section{PROCESSING AND EVALUATION OF NICKEL CLADDINGS}

\subsection{SELECTION AND PROCESSING OF NICKEL CLADDINGS}

After a careful examination of the capabilities, advantages, and disadvantages of the various technologies along with the needs for FHR components, two cladding technologies were selected for initial cladding trials. These are (1) a laser-based surface cladding technique that is primarily applicable to coat surfaces with line-of-sight access and (2) CVD using the nickel-carbonyl process that is applicable to the cladding of surfaces with no line-of-sight access, such as long, narrow tubes used in heat exchangers. Very few techniques have the capability to coat surfaces with no line-ofsight access, and hence the nickel-carbonyl process was a preferred technique for cladding such surfaces. A number of techniques could satisfy the required criteria for cladding surfaces with line-ofsight access; in this case, preference was given to techniques for which the technology is readily available at Oak Ridge National Laboratory. Brief descriptions of the two processing techniques used in this work are presented below.

\subsubsection{Laser-Based Surface Cladding}

In the laser-based cladding technique, the surface to be clad is initially spray-coated with a highpurity nickel powder mixed with a polymer-based binder. In this case, spherical nickel powder -325 mesh 99.9\% (AEE part\# NI-120) was used for the coatings. Following an initial bake of the precursor, a high powered Nd-YAG laser is used to rapidly heat the surface layer to a temperature sufficient to melt it. The laser used for this project was a Trumpf HL4006D with a 4kW $1064 \mathrm{~nm}$ continuous Nd:YAG beam connected to a fabricated brass water-cooled lens assembly. The laser beam diverges from the $600 \mu \mathrm{m}$ fiber into the focusing optics at an angle of $25 \mathrm{mRad}$. The beam is then passed through a series of 3 lenses housed in a custom water cooled brass fixture. The divergent beam is translated into a parallel round beam by a plano-convex lens at a predetermined distance from the tip of the fiber. The beam is next focused in the direction perpendicular to its travel direction by a planoconcave lens, and is focused again in the direction parallel to its travel direction by another planoconcave lens placed in relation to the previous lens. The beam then travels through a clear protective slide, and makes contact with the sample. When focused, the approximate dimensions of the beam are $1 \mathrm{~mm} \times 10 \mathrm{~mm}$. The laser beam scans continuous offset tracks across the sample's surface horizontally, until the full surface is processed. Depending on the amount of heat supplied, a small portion of the substrate is also melted at the same time, which allows intimate mixing between the precursor layer and the substrate layer. Due to the relatively small size of the laser beam, the beam is rastered on the surface of the specimen in order to cover areas larger than the beam diameter. Figure 2 shows a picture of the laser processing setup. Table 9 shows a summary of the parameters used for processing the coatings. Primary processing that was changed during the trials was the laser power used for processing of the coatings. The linear travel speed of the laser was held constant and both alloy 617 substrates and alloy $800 \mathrm{H}$ substrates were used for processing. Compositions of the two alloys are shown in Table 10. Figure 3 shows an optical image of a small block of nickel-based alloys coated on the top surface using a laser-based technique. 


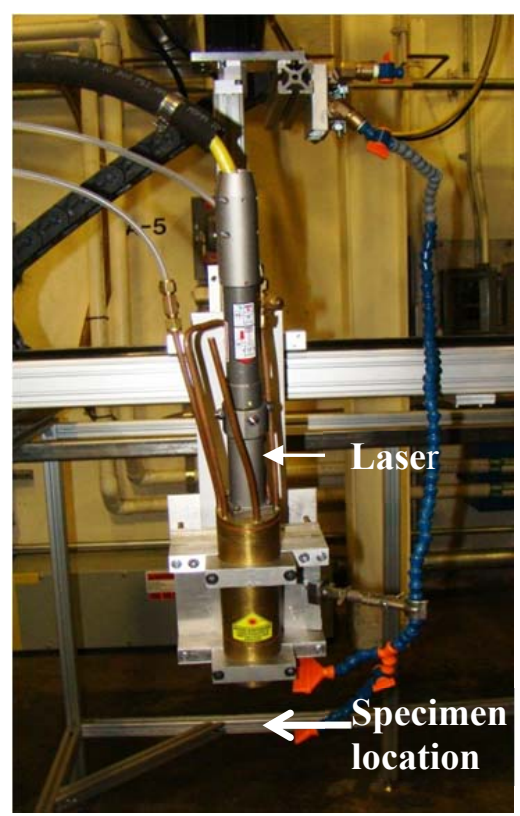

Fig 2. Image of the laser setup used for laser processing of claddings.

Table 9. Summary of processing conditions used for laser processing of Ni coatings on nickel based alloy substrates.

\begin{tabular}{ccccc}
\hline Power (watts) & $\begin{array}{c}\text { Cladding } \\
\text { Thickness }(\boldsymbol{\mu m})\end{array}$ & Substrate Alloy & $\begin{array}{c}\text { Substrate } \\
\text { Thickness (in) }\end{array}$ & Cover Gas \\
\hline 2500 & 100 & 617 & $0.2 ”$ & Argon \\
3000 & 100 & 617 & $0.2 ”$ & Argon \\
3500 & 100 & 617 & $0.2 ”$ & Argon \\
4000 & 100 & 617 & $0.2 ”$ & Argon \\
2500 & 100 & $800 \mathrm{H}$ & $0.5 ”$ & Argon \\
3000 & 100 & $800 \mathrm{H}$ & $0.5 ”$ & Argon \\
3500 & 100 & $800 \mathrm{H}$ & $0.5 ”$ & Argon \\
4000 & 100 & $800 \mathrm{H}$ & $0.5 ”$ & Argon \\
\end{tabular}

Table 10. Nominal Compositions of alloy substrates used in the study.

\begin{tabular}{lllllllllll}
\hline Alloy & Ni & Fe & Cr & Mn & Co & Cu & Mo & Si & Ti & Al \\
\hline 617 & 54.9 & 1 & 21.4 & 0 & 12.8 & 0 & 8.5 & 0.1 & 0.1 & 1.2 \\
$800 \mathrm{H}$ & 31.1 & 45.3 & 21.6 & 0.7 & 0.3 & 0.5 & 0 & 0.3 & 0 & 0.2
\end{tabular}




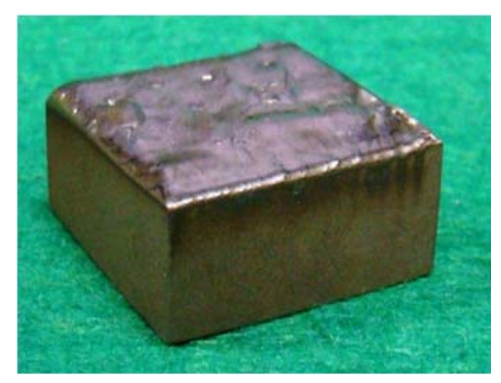

Fig 3. Optical image of a Ni-based alloy substrate with a Ni cladding applied using a laser-based surface cladding technique.

\subsubsection{Chemical Vapor Deposition of Nickel}

In order to assess the deposition quality and adhesion properties of nickel coatings applied onto highstrength nickel alloys chemical vapor deposition (CVD), samples of Alloy $800 \mathrm{H}$ and Inconel ${ }^{\mathrm{TM}} 617$ were CVD coated by Chemical Vapor Metal Refining Inc., a commercial vendor.The deposition process selected was a metal-organic chemical vapor deposition (MOCVD) process based on the nickel carbonyl process developed in 1889 by Ludwig Mond and his coworker Carl Langer and Friedrich Quincke ${ }^{16}$. In this process four molecules of carbon monoxide are reacted with active nickel to form a colorless gas, nickel tetracarbonyl, as shown in equation 1 at temperatures between 40 and $100^{\circ} \mathrm{C}$

$$
\mathrm{Ni}+4 \mathrm{CO} \stackrel{50^{\circ} \mathrm{C}}{\longrightarrow} \mathrm{Ni}(\mathrm{CO})_{4}
$$

Nickel tetracarbonyl decomposes back into nickel and carbon monoxide at temperatures between 150 and $300{ }^{\circ} \mathrm{C}$ and this process can be used to deposit nickel on desired surfaces. Generally, at temperatures below $200{ }^{\circ} \mathrm{C}$ nickel deposits onto surfaces and at temperatures above $220{ }^{\circ} \mathrm{C}$ nickel powder is produced.

The nickel carbonyl formation and decomposition reactions are exploited to form conformal nickel layers on substrates by first forming the nickel tetracarbonyl gas and then decomposing the gas on a heated substrate in a reaction chamber. The process is illustrated in Figure 4. The nickel deposition rate depends primarily on the delivery rate of the precursor nickel tetracarbonyl gas to the surface, as the decomposition reaction is rapid relative to the gas motion. Deposition is done at elevated pressure, and deposition rates typically vary from $250 \mu \mathrm{m}$ to $750 \mu \mathrm{m}$ per hour. Typical carbon contamination within the deposited nickel is about $60 \mathrm{ppm}$. Since this deposition is performed from the vapor phase, conformal coatings can be applied using the MOCVD process and hence can be used to coat complex shapes. The only shape restriction for the process is related balancing gas flow dynamics to the reaction rate of the nickel tetracarbonyl gas with the substrate. Essentially the gas composition, flow rate, and reaction temperature must be optimized to ensure that uniform composition gas reaches all portions of deep shapes such as capillary tubing or only the inlet portions of the tube will be coated. 


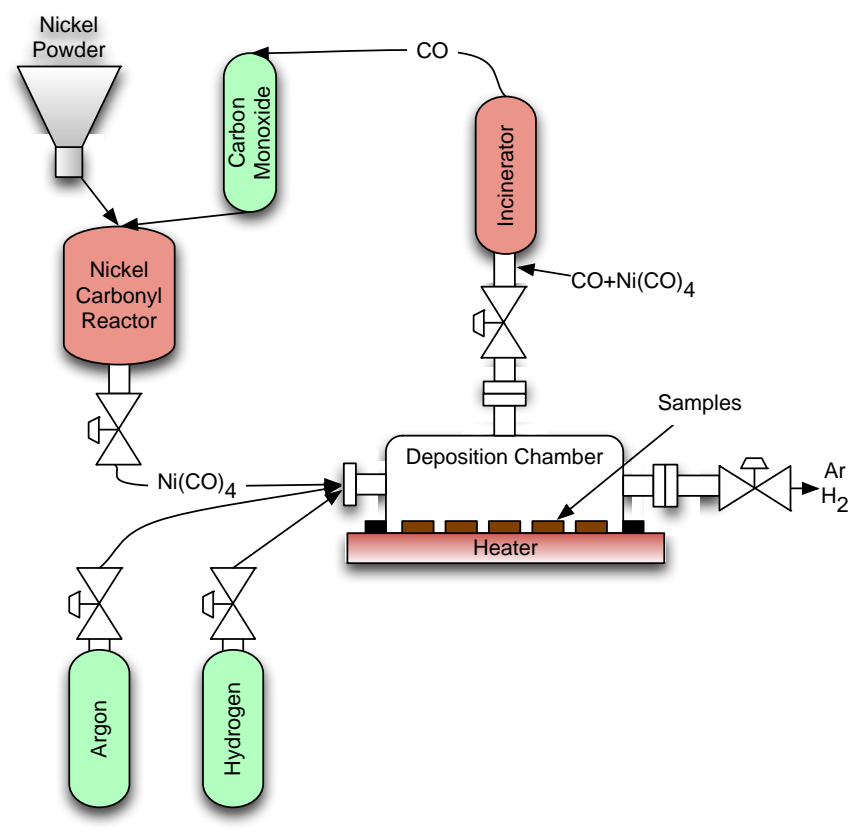

Fig 4. Schematic layout of the Ni tetracarbonyl deposition process.

Five samples ( $25 \times 6 \times 6 \mathrm{~mm})$ of Inconel ${ }^{\mathrm{TM}} 617$ and Alloy $800 \mathrm{H}$ were clad with nickel. In an effort to remove any surface contamination, the alloys were first placed into the deposition chamber made from a copper tube with a ceramic heater element, and equipped with inlet and outlet fixtures for the necessary gases. The chamber was purged with argon followed by hydrogen. While filled with hydrogen, the chamber was heated to $375^{\circ} \mathrm{C}$ and held for 40-60 minutes to remove any surface organic contamination. Note this process may not remove the thin, native chromium oxide protective layer formed on the surface of the alloys. The effectiveness of this layer in serving as a barrier to chromium diffusion should be evaluated in future studies. Alloy 617 specimens were processed for 8 hours at $200{ }^{\circ} \mathrm{C}$ at a pressure of $300 \mathrm{kPa}$ and Alloy $800 \mathrm{H}$ specimens were processed for 2 hours at $200{ }^{\circ} \mathrm{C}$ at a pressure of $500 \mathrm{kPa}$. After the deposition processes were completed, the system was purged with argon and allowed to cool down. An optical image of three MOCVD coated specimens is shown in Fig. 5.

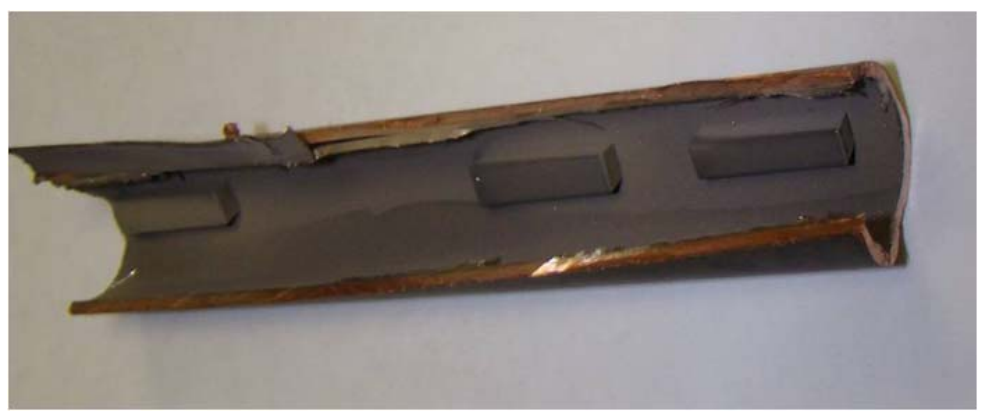

Fig 5. Optical image of three Ni-based substrates coated using the CVD nickel-carbonyl process.

\subsection{CLADDING EVALUATIONS}

Claddings applied by means of the selected processes were subject to a preliminary evaluation focused on the following criteria: 
- Composition of cladding and mixing between substrate and cladding

- Presence of pinholes, voids, surface cracks, and significant internal cracks;

- Uniformity in thickness;

- Microstructure of cladding and the near-surface substrate region;

- Presence or absence of debonding at the interface between the cladding and the substrate; and

- Hardness of the cladding and comparison with that of the substrate.

The results of the evaluation are provided in sections 5.3

\subsubsection{Laser Claddings}

Figures 6 (a), 7 (a), 8 (a), and 9(a) show optical images of the alloy 617 substrates coated with nickel cladding at laser powers of $2500 \mathrm{~W}, 3000 \mathrm{~W}, 3500 \mathrm{~W}$, and $4000 \mathrm{~W}$ respectively while figures $6(\mathrm{~b}), 7$ (b), 8 (b), and 9 (b) show optical images of cross-sections following the cladding process. Figures 10 (a), 11 (a), 12 (a), and 13(a) show optical images of the alloy $800 \mathrm{H}$ substrates coated with nickel cladding at laser powers of $2500 \mathrm{~W}, 3000 \mathrm{~W}, 3500 \mathrm{~W}$, and $4000 \mathrm{~W}$ respectively while figures $10(\mathrm{~b}), 11$ (b), 12 (b), and 13(b) show optical images of cross-sections following the cladding process. In all cases, the clad surface in figure (b) is on top.

The following are the major observations concerning the claddings and the substrate obtained from these micrographs. In general, the quality of claddings was acceptable with occasional presence of few voids, pinholes, and cracks. These were regions in which the coatings had spalled; it is anticipated that optimization of the process would minimize these spalled regions. In addition, good adhesion along with good mixing was present at the interface between the cladding and the substrate. A portion of the substrate from the near-surface region was observed to have melted and intermixed with the cladding material. As expected, the size of this region increased with increasing laser power indicated by the larger differently etched region in pictures shown above.
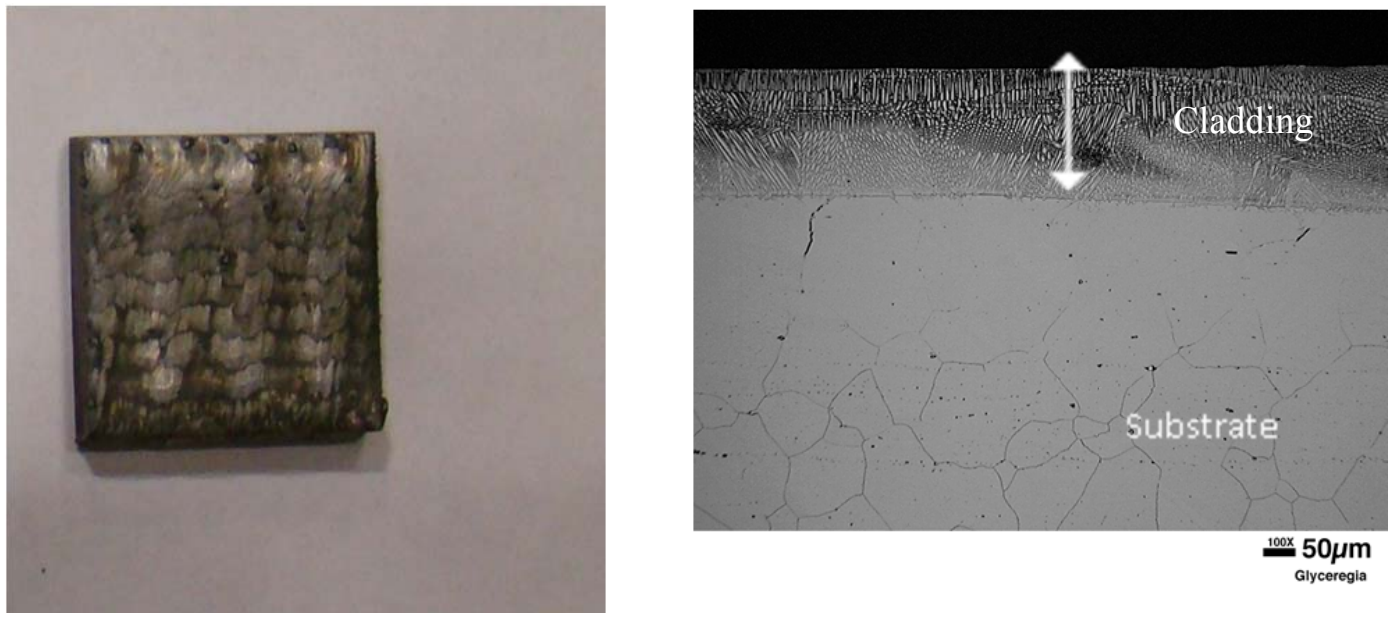

Fig 6. (a) Optical image of the Ni cladding processed on an Alloy 617 substrate using a laser power of 2500W. (b) Cross-sectional optical microscopy of sample shown in (a). 

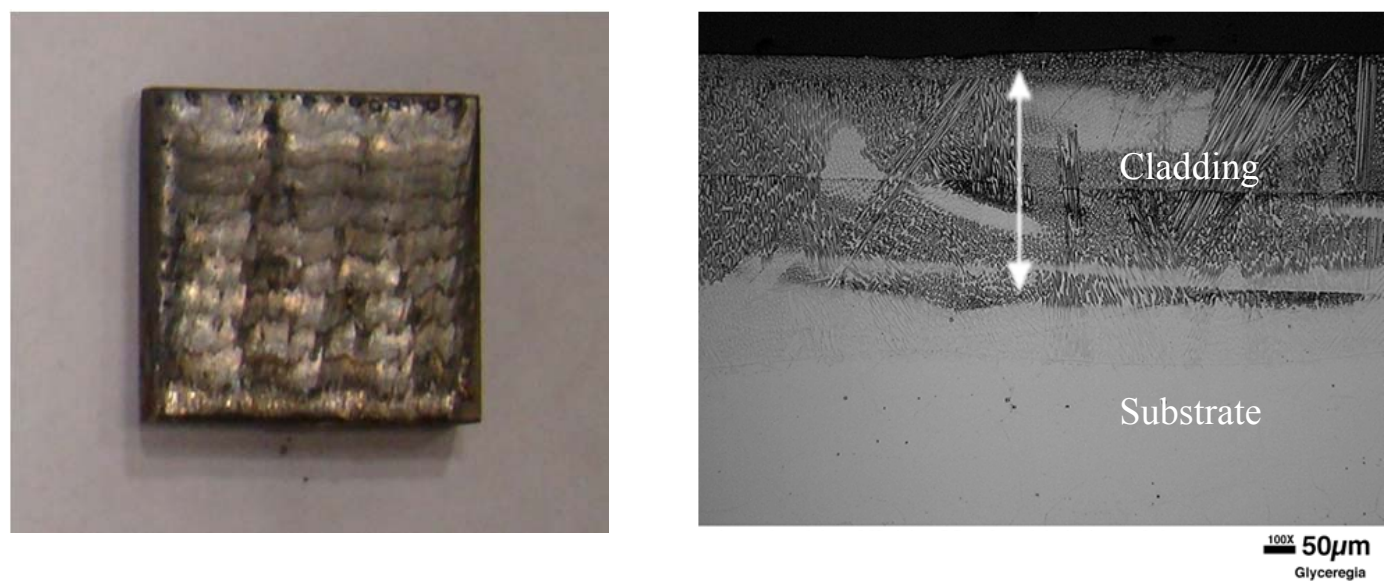

Fig 7. (a) Optical image of the Ni cladding processed on an Alloy 617 substrate using a laser power of 3000W. (b) Cross-sectional optical microscopy of sample shown in (a).
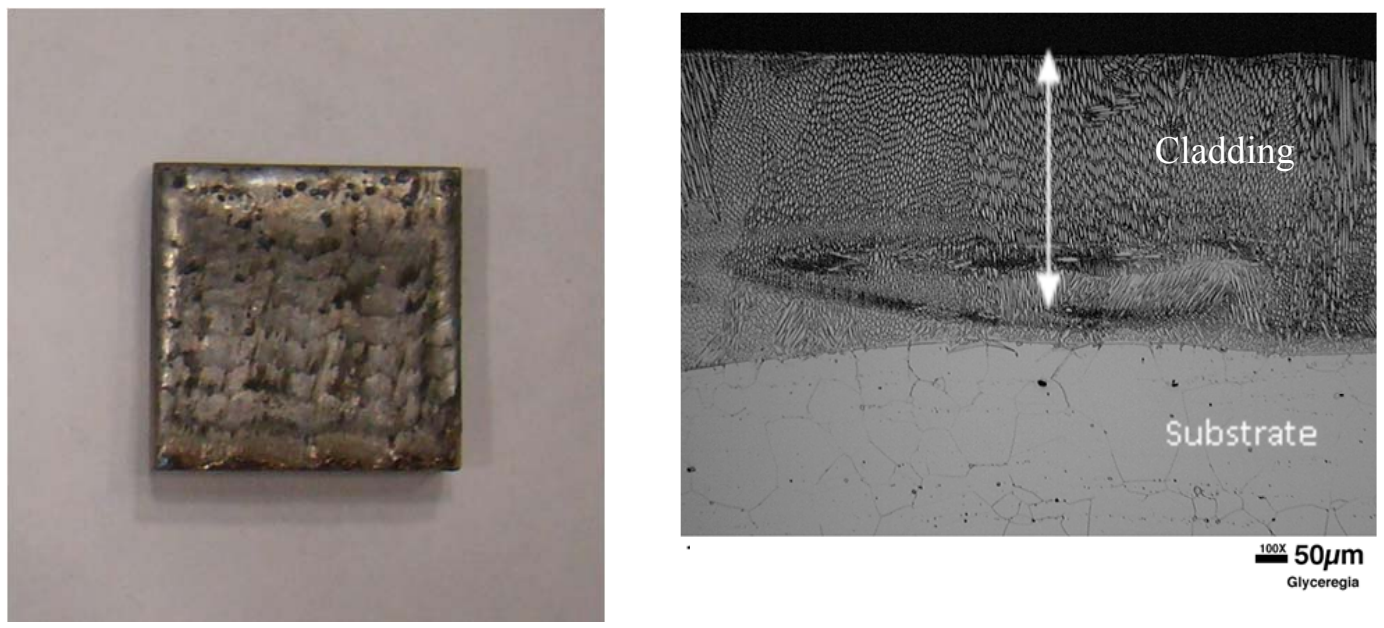

Fig 8. (a) Optical image of the Ni cladding processed on an Alloy 617 substrate using a laser power of 3500W. (b) Cross-sectional optical microscopy of sample shown in (a). 

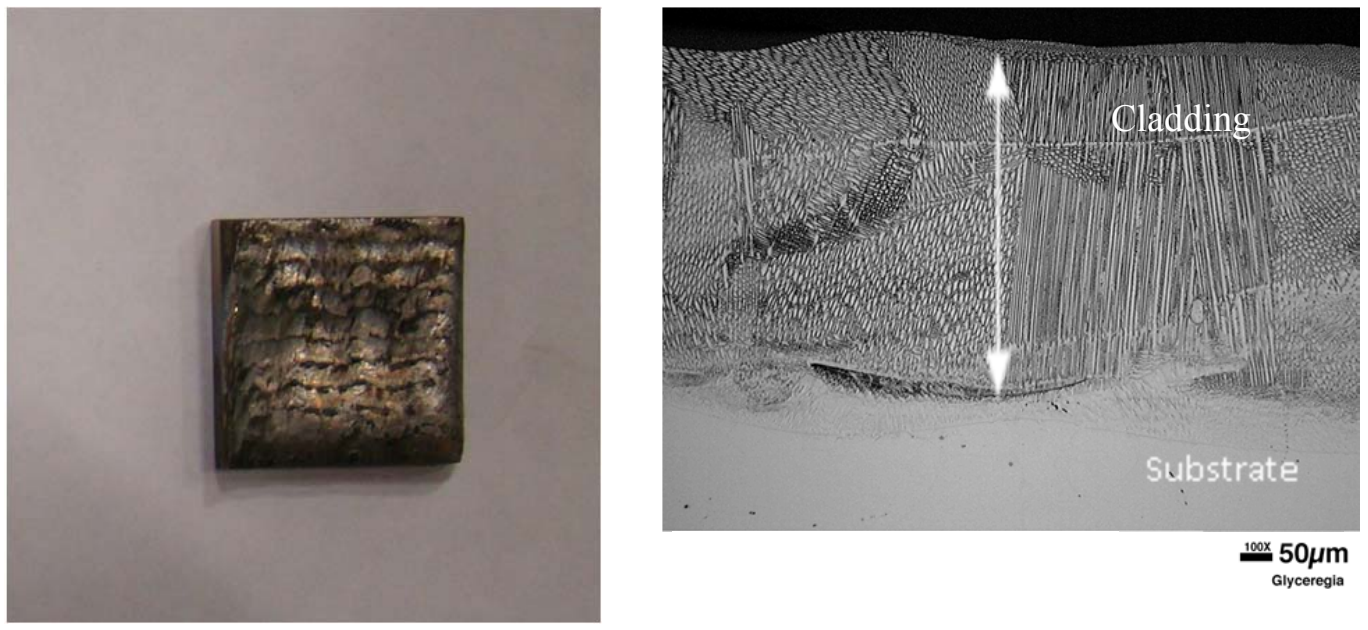

Fig 9. (a) Optical image of the Ni cladding processed on an Alloy 617 substrate using a laser power of 4000W. (b) Cross-sectional optical microscopy of sample shown in (a).
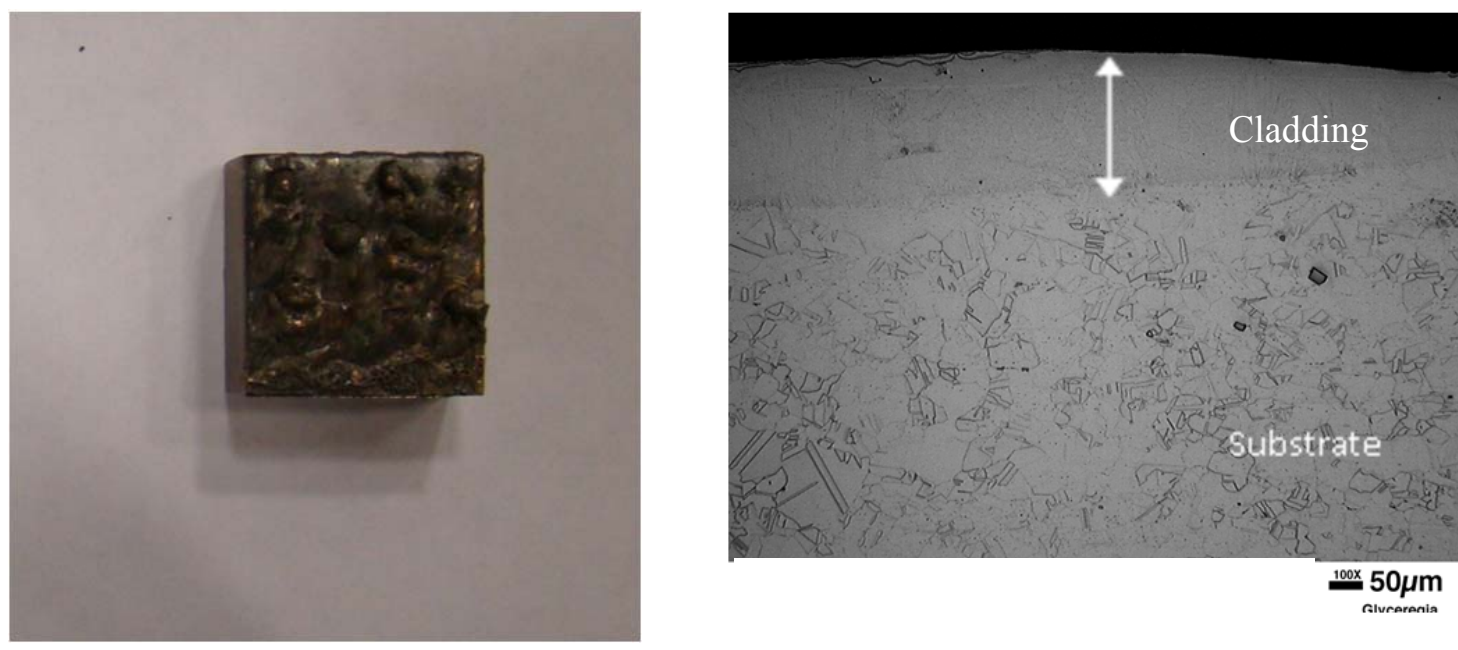

Fig 10. (a) Optical image of the Ni cladding processed on an Alloy $800 \mathrm{H}$ substrate using a laser power of 2500W. (b) Cross-sectional optical microscopy of sample shown in (a). 

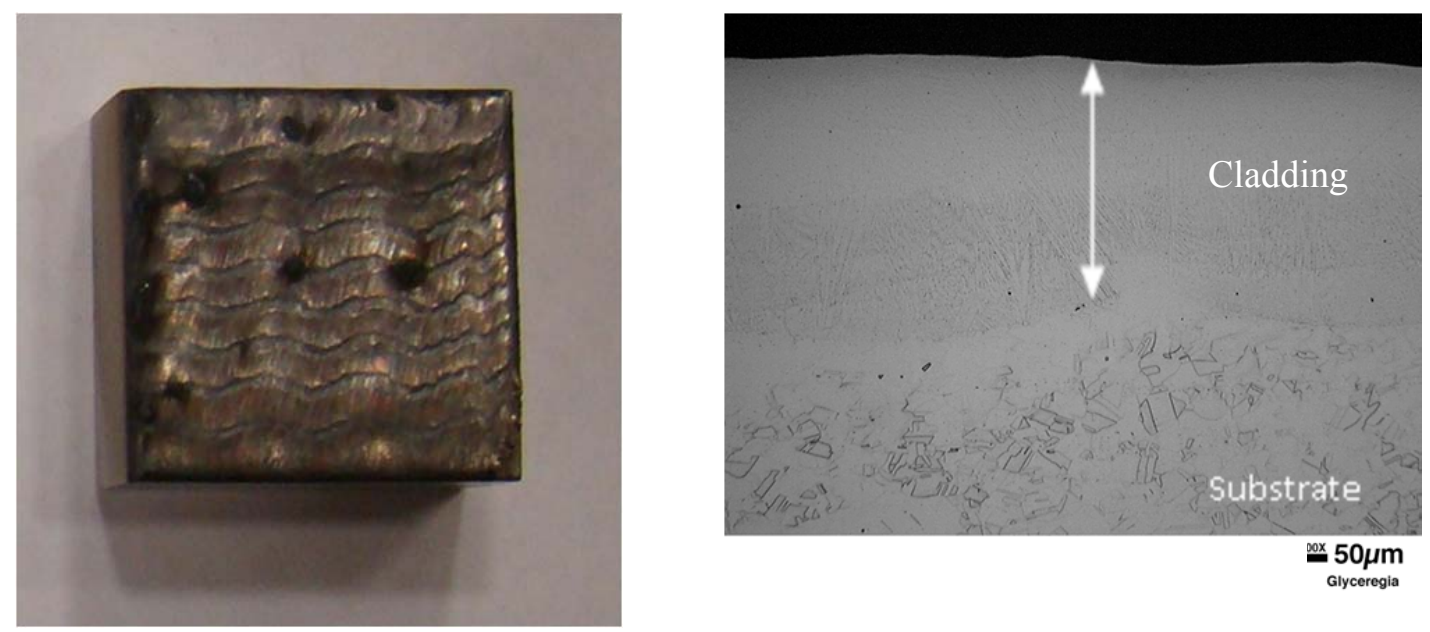

Fig 11. (a) Optical image of the Ni cladding processed on an Alloy $800 \mathrm{H}$ substrate using a laser power of 3000W. (b) Cross-sectional optical microscopy of sample shown in (a).
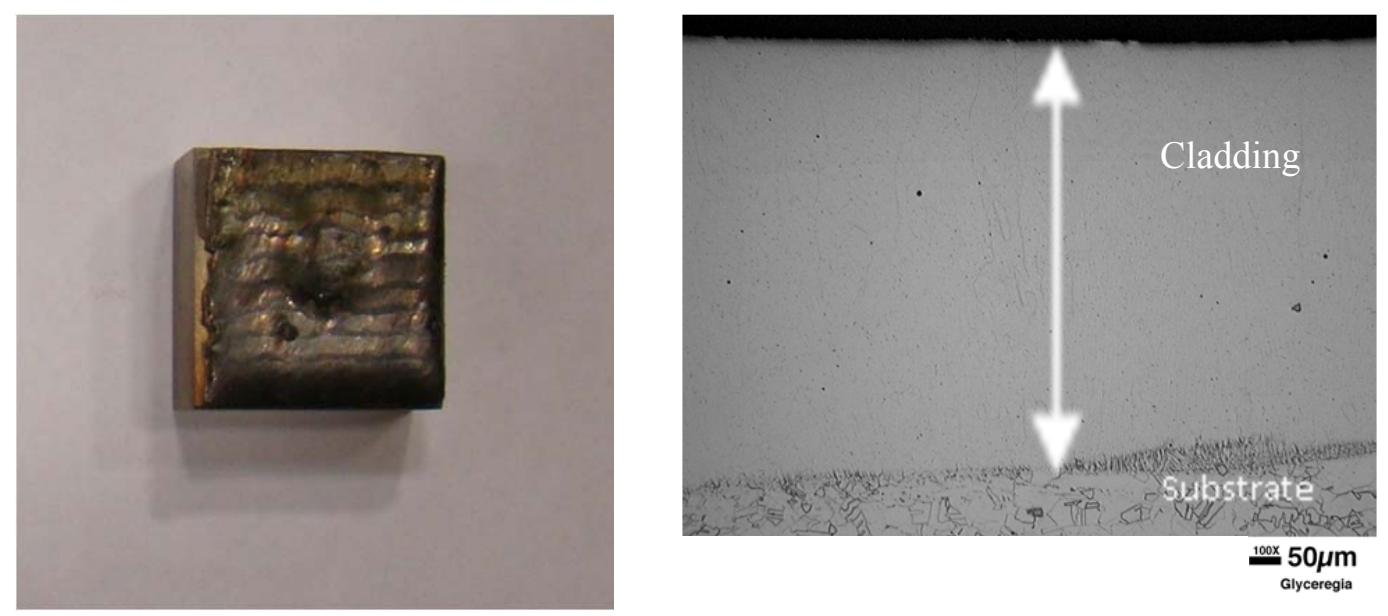

Fig 12. (a) Optical image of the Ni cladding processed on an Alloy $800 \mathrm{H}$ substrate using a laser power of 3500W. (b) Cross-sectional optical microscopy of sample shown in (a). 

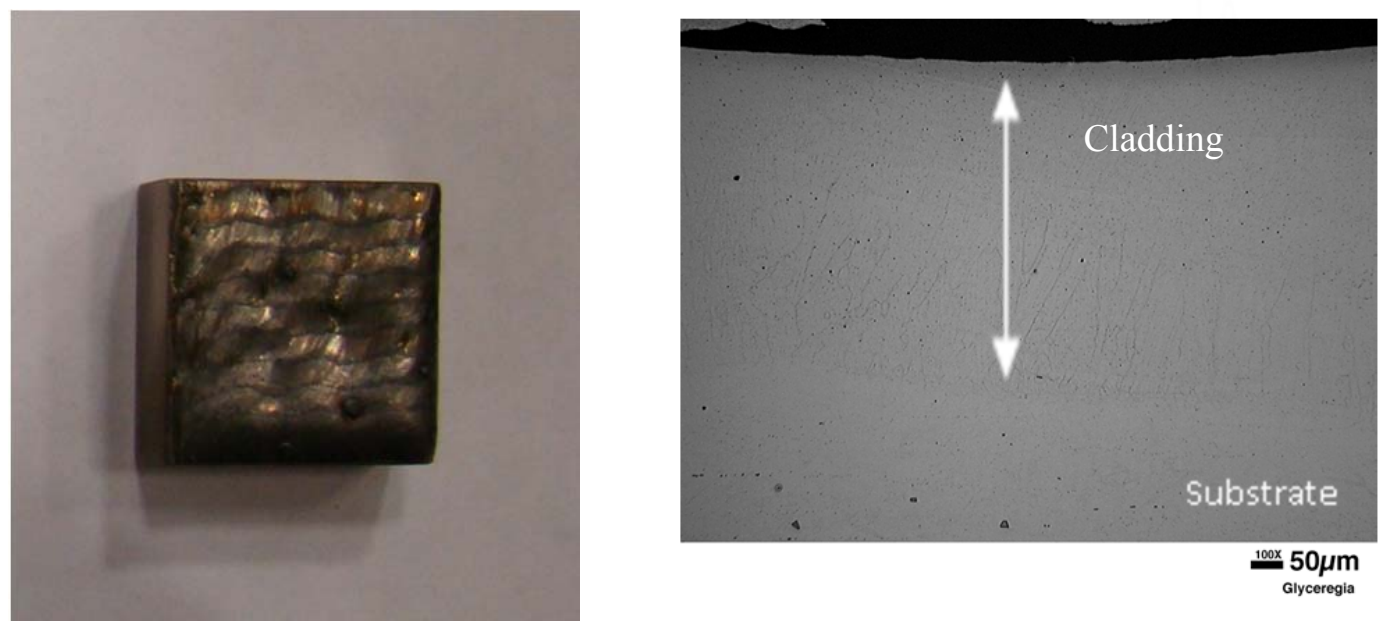

Fig 13. (a) Optical image of the Ni cladding processed on an Alloy $800 \mathrm{H}$ substrate using a laser power of 4000W. (b) Cross-sectional optical microscopy of sample shown in (a).

To understand the effect of processing parameters on the composition of the cladding layer induced by mixing between the nickel cladding and the substrate, compositions of the near surface region and at the substrate near the interface were measured using Wavelength Dispersive Spectroscopy (WDS) using a line scan as shown in figure 14 (a). Figures 14 and 15 show the composition within the cladding and the 617 substrate processed using $2500 \mathrm{~W}$ and $4000 \mathrm{~W}$ laser power respectively, while Figures 16 and 17 show the composition within the cladding and the $800 \mathrm{H}$ substrate processed using 2500W and 4000W laser power respectively.
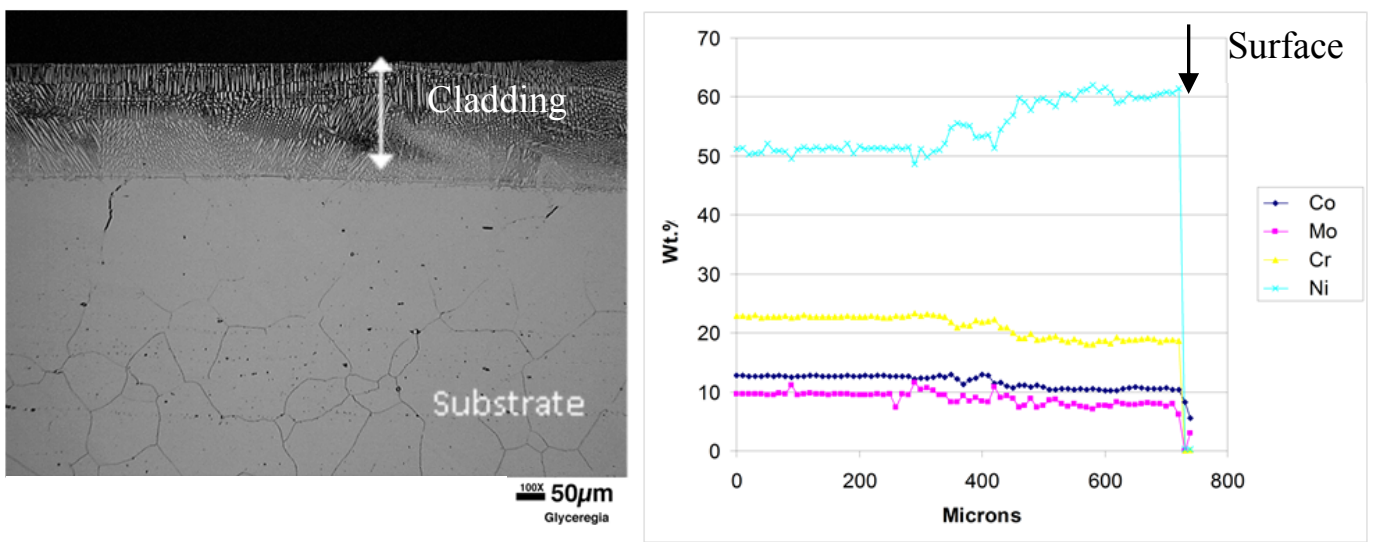

Fig 14. (a) Cross-sectional optical microscopy of Ni cladding processed on an Alloy 617 substrate using a laser power of $2500 \mathrm{~W}$. (b) Measured composition profile along a line shown in 14 (a). The composition of the top surface is shown on the right. 

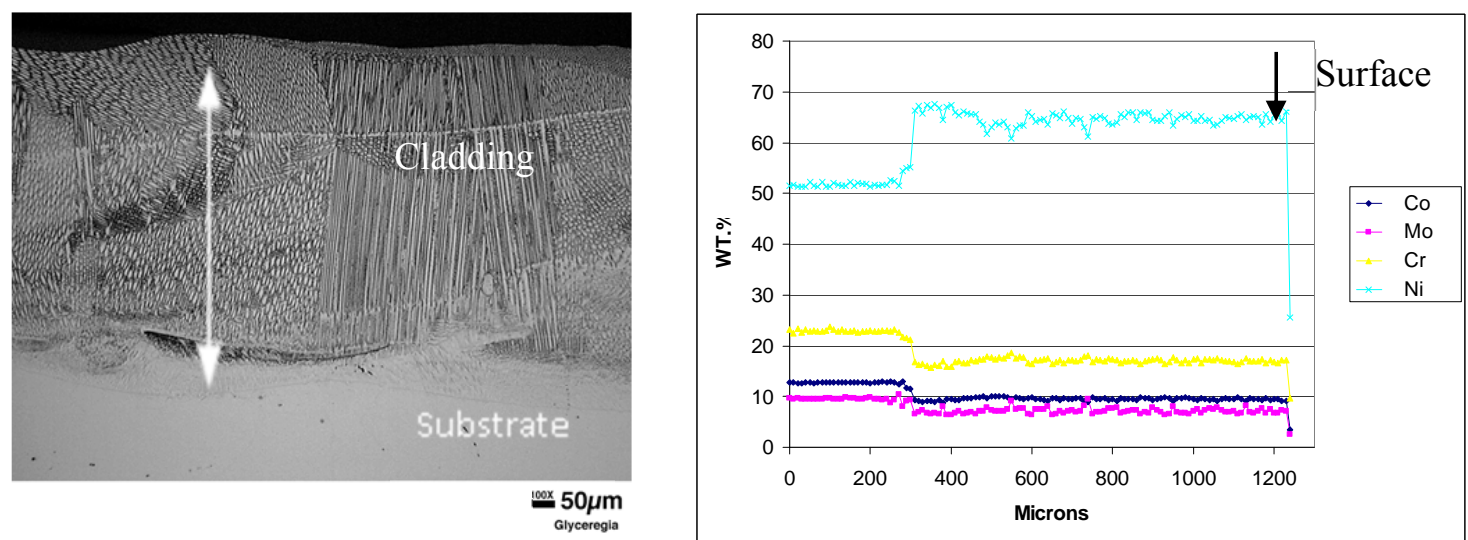

Fig 15. (a) Cross-sectional optical microscopy of Ni cladding processed on an Alloy 617 substrate using a laser power of $4000 \mathrm{~W}$. (b) Measured composition profile along the line shown in (a). The composition of the top surface is shown on the right.

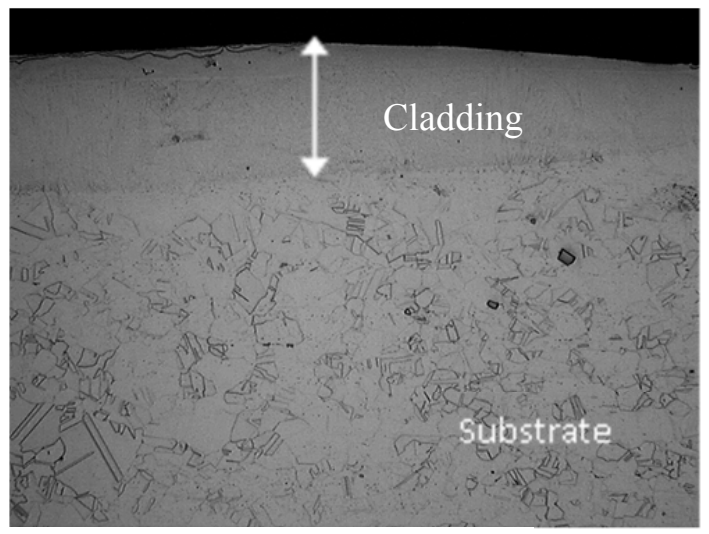

100x $50 \mu \mathrm{m}$

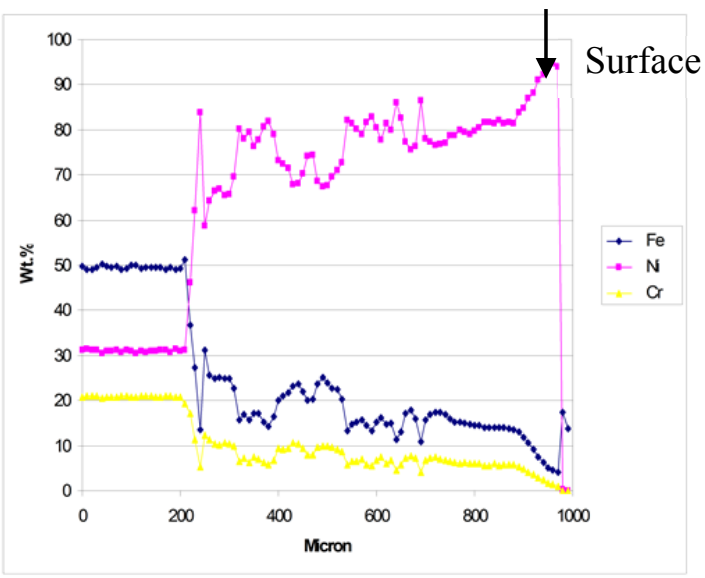

Fig 16. (a) Cross-sectional optical microscopy of Ni cladding processed on an Alloy $800 \mathrm{H}$ substrate using a laser power of $2500 W$. (b) Measured composition profile along a line shown in (a). The composition of the top surface is shown on the right.
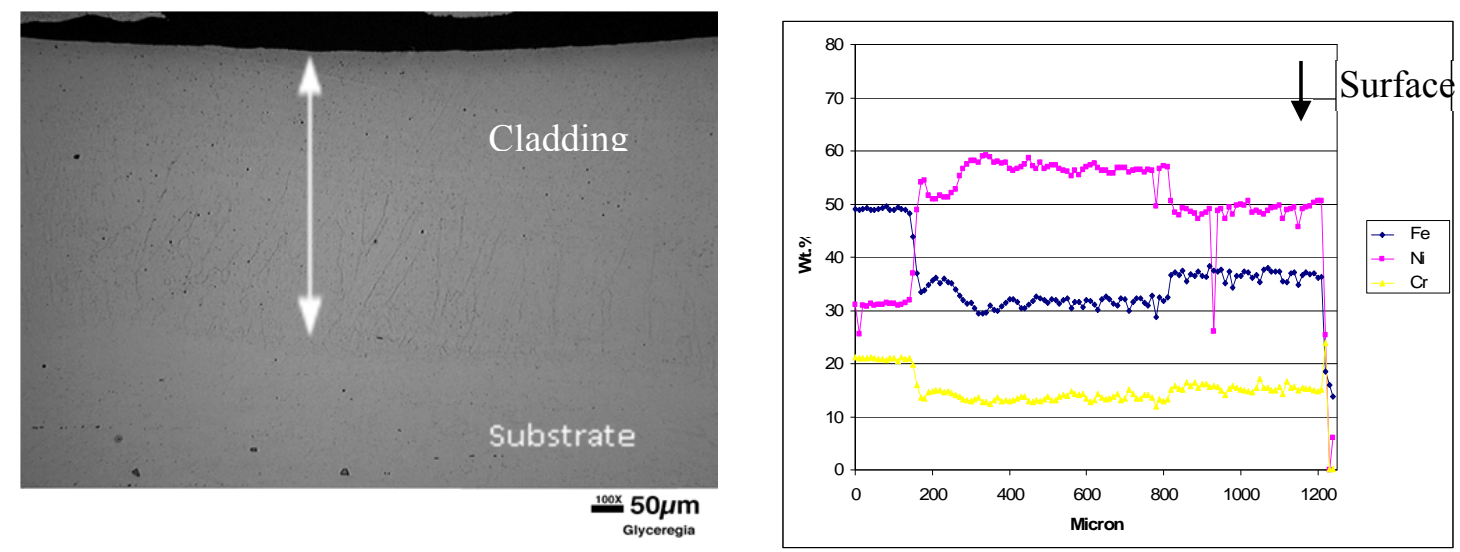

Fig 17. (a) Cross-sectional optical microscopy of Ni cladding processed on an Alloy $800 \mathrm{H}$ substrate using a laser power of $4000 \mathrm{~W}$. (b) Measured composition profile along a line shown in 16 (a). The composition of the top surface is shown on the right. 
A careful study of the composition of the cladding layer in Figure 14 (b) shows that the composition of this layer is rich in nickel and also, contains a significant amount of chromium, cobalt, and molybdenum. This results from the melting of a fraction of the substrate underneath the nickel layer and subsequent mixing between the molten nickel layer and the molten substrate layer followed by solidification. Figure 14 (b) also shows that due to dilution with pure nickel, the chromium levels within the cladding layer $(\sim 18 \mathrm{wt} . \%)$ are lower than that within the substrate $(\sim 21.6 \mathrm{wt} . \%)$. The region in which the chromium levels are lower than the substrate extends to about 400 microns from the top surface. Figure 14 (b) shows the composition within the cladding layer and the substrate layer when processed with a higher laser power, $4000 \mathrm{~W}$. As would be expected, the fraction of the substrate layer that melts during the processing increases with increasing laser power. It is clear from this figure that the chromium, molybdenum, and the cobalt levels stay fairly constant over a region that is 900 micron thick below the surface. In contrast, the cladding layer processed using $2500 \mathrm{~W}$ shows gradients in the nickel (and hence chromium, cobalt, and molybdenium) in the near-surface region. It should also be noted that the nickel level in this layer is about $65 \mathrm{wt}$. \% compared to that of $\sim 53 \%$ in the substrate and seems to be higher than that in the nickel layer processed with lower power. Thus, higher laser power results in the melting of a larger fraction of the substrate, a greater dilution within the cladding layer, and a deeper penetration of the effect of the laser processing on the substrate. Further process optimization is required to reduce the chromium, cobalt, and molybdenum at the surface and to retain a high nickel region. Feasibility of achieving these targets is demonstrated with cladding on alloy $800 \mathrm{H}$ as outlined below.

Figure 16 (b) and 17 (b) show the composition within the cladding layer and the $800 \mathrm{H}$ substrate processed using $2500 \mathrm{~W}$ and $4000 \mathrm{~W}$ laser power respectively. Composition measurements show that the cladding layer is again rich in nickel at both power levels shown in the figures. In addition, the cladding processed with a laser power of $2500 \mathrm{~W}$ shows that the nickel, iron, and chromium levels vary from the surface of the cladding layer to the interior. The highest levels of nickel are observed close to the surface while the lower levels of nickel are observed closer to the substrate-cladding interface. In contrast, iron and chromium levels are larger at the substrate-matrix interface and their levels decrease closer to the surface. The chromium and iron levels close to the surface are significantly lower in the first $200 \mu \mathrm{m}$ region near the surface $(\sim 1.0-6.0 \mathrm{wt} . \% \mathrm{Cr}, \sim 4.0-15.0 \mathrm{wt} . \%$ $\mathrm{Fe}$ ) which demonstrates that the laser surface processing can achieve the targets for surface modification by achieving a nickel rich layer. Furthermore, the chromium levels are below $10 \mathrm{wt} . \%$ within the first $800 \mu \mathrm{m}$ of the cladding layer which shows that with the selection of process parameters, the amount of elements such as chromium can be retained at desirable levels. With the use of higher laser power, the depth over which the nickel is distributed increases, and the pronounced nickel concentration gradient in the cladding layer decreases resulting in a more uniform distribution of alloying elements with this layer. Again, the levels of iron and chromium within the cladding layer increases with increasing power, thus demonstrating the importance of process parameters in controlling the composition of the cladding layer. Thus, it can be concluded that the laser processing can be successfully used to modify the surface composition of Alloy 617 and Alloy $800 \mathrm{H}$ with appropriate selection of process parameters. Future work should include optimization of the process parameters towards achieving the desired compositions of the various elements within the cladding layer.

The effect of process parameters on the microhardness of the cladding and the hardness of the substrate close to the cladding was evaluated. Figures 18 and 19 show the variation in Vickers microhardness within the cladding and the 617 and $800 \mathrm{H}$ substrates respectively, for the claddings processed using the highest laser power level of $4000 \mathrm{~W}$. Note that for both substrates, the microhardness values increase as the distance from the surface increases (excluding any edge effects). Furthermore, microhardness values in the cladding and in the matrix near the interface were found to be greater than that in the matrix away from the interface. For example, the average microhardness of 
the matrix in Alloy 617 was found to be $220 \mathrm{Hv}$ whereas the microhardness values in the cladding and in the nearby substrate were found to be between 216 and 271. In alloy $800 \mathrm{H}$, the microhardness values in the cladding and nearby matrix was found to be between 181 and $208 \mathrm{Hv}$ while the value in the matrix was found to be $165 \mathrm{Hv}$.
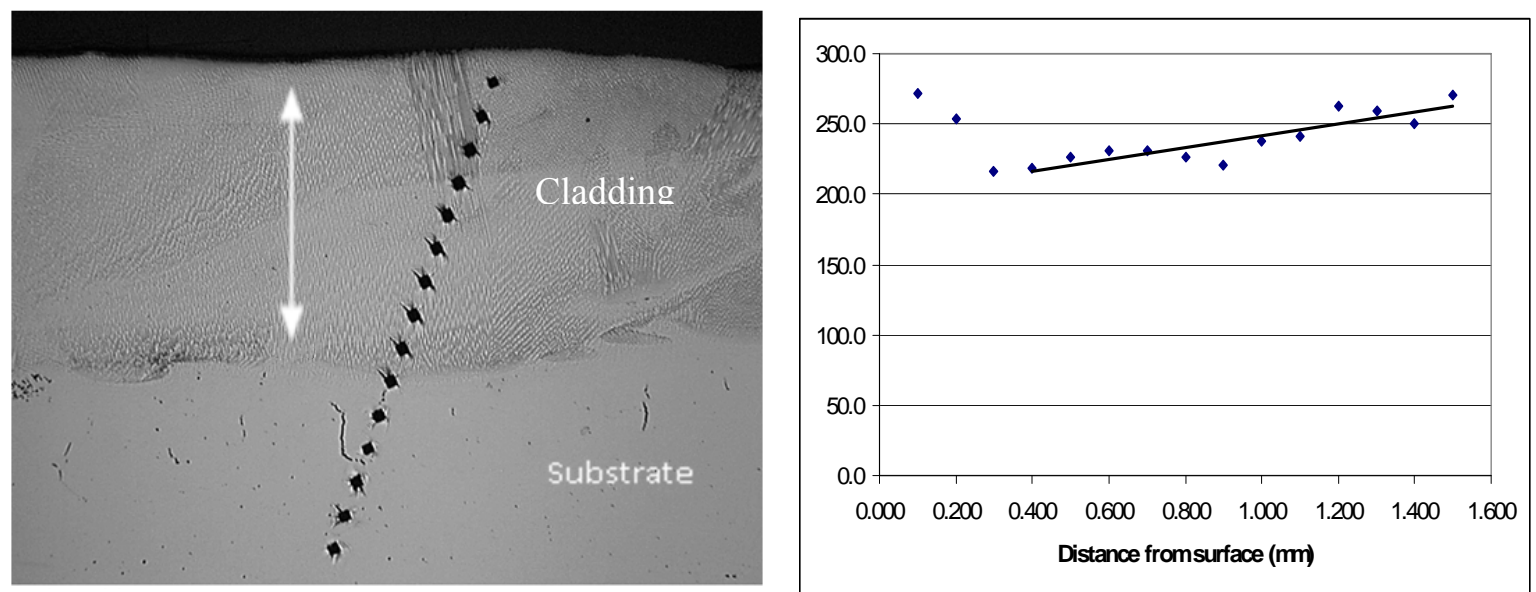

50x $100 \mu \mathrm{m}$

Fig 18. (a) Cross-sectional optical microscopy of Ni cladding processed on an Alloy 617 substrate using a laser power of $4000 \mathrm{~W}$. (b) Measured microhardness profile along a line shown in (a). Line is a visualization aid.
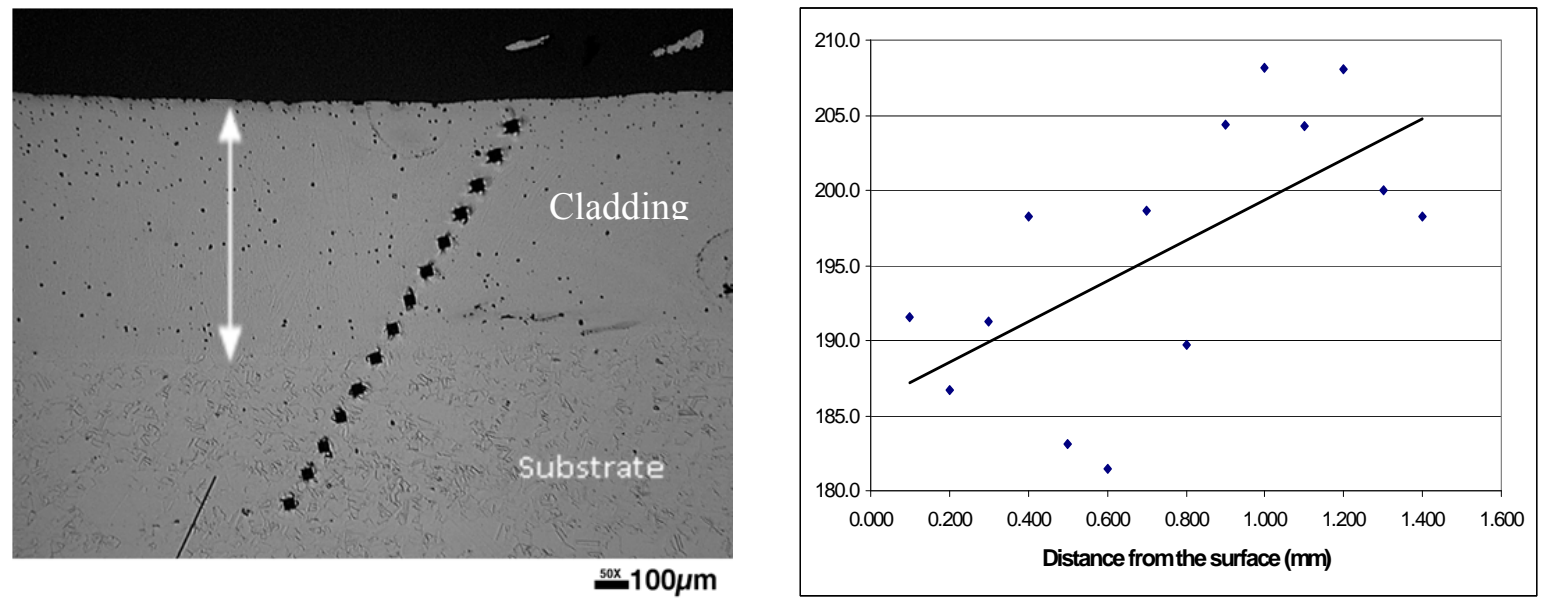

Fig 19. (a) Cross-sectional optical microscopy of Ni cladding processed on an Alloy $800 \mathrm{H}$ substrate using a laser power of $4000 \mathrm{~W}$. (b) Measured microhardness profile along a line shown in (a). Line is a visualization aid. 


\subsubsection{Chemical Vapor Deposited Claddings}

Figure 20 shows cross-sectional optical microscopy images of nickel layers deposited using the MOCVD process. Figure 20 (a) shows the layer deposited on an Alloy $800 \mathrm{H}$ substrate (processing condition 1), while Figure 20 (b) shows the layer deposited on an Alloy 617 substrate (processing condition 2). As evident from the figures, relatively thick layers have been deposited using both conditions. SEM observations show the presence of an interface layer between the deposited layer and the matrix. This layer is likely the oxide layer that was present on the matrix prior to deposition of coating. The presence of this oxide layer could affect the adhesion between the cladding and the matrix. The effect of this layer on adhesion should be the subject of future studies. Future studies should also evaluate processes for removing this oxide layer to facilitate intimate mixing between the cladding and the matrix. Figure 21 shows composition profiles across the cladding layers shown in Figure 20.
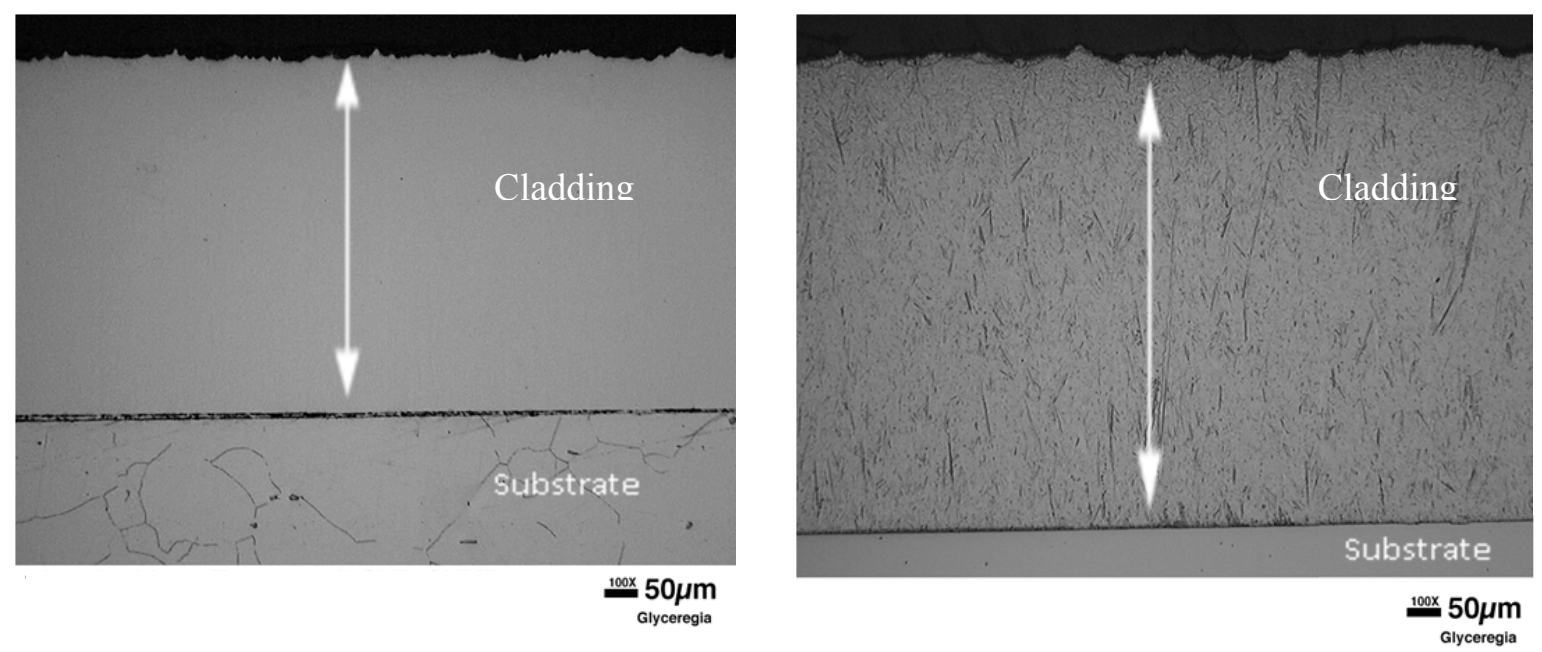

Fig 20. (a) Cross-sectional optical microscopy of Ni cladding processed on an Alloy $800 \mathrm{H}$ substrate (test 1). (b) Cross-sectional optical microscopy of Ni cladding processed on an Alloy 617 substrate (test 2).
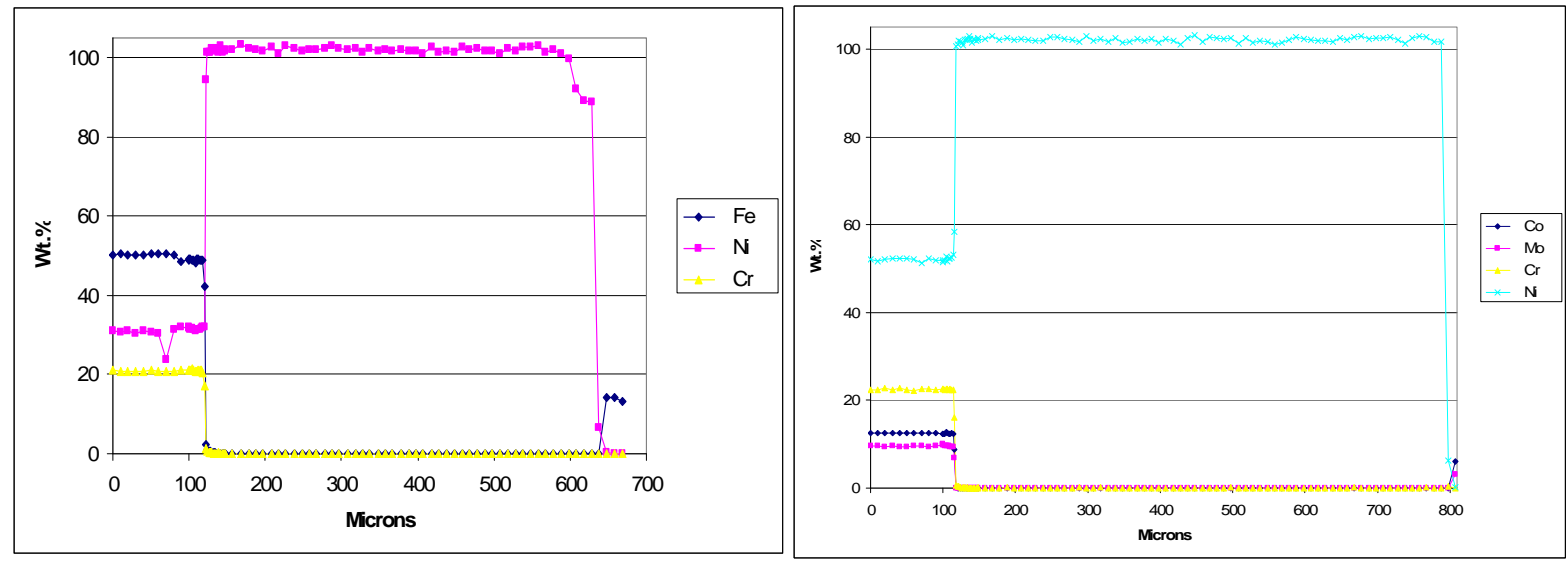

Fig 21. (a) Cross-sectional optical microscopy of Ni cladding processed on an Alloy $800 \mathrm{H}$ substrate (test 1). (b) Cross-sectional optical microscopy of Ni cladding processed on an Alloy 617 substrate (test 2). 
Composition profile presented in figure 20 (a) shows that the thickness of the nickel cladding deposited was about $0.6 \mathrm{~mm}$ while that in figure 20 (b) was about $0.75 \mathrm{~mm}$. Comparison of the nickel profiles shown in figure 20 with that shown in figures 16 and 17 show the difference between the two types of processes. Note that due to the lower processing temperatures, the composition profiles observed in claddings deposited using chemical vapor deposition are sharp with little or no mixing between the nickel cladding layer and the substrate. This, as pointed out earlier, is one of the advantages of the chemical vapor deposition process. It should be noted that high temperature exposure will result in interdiffusion and the effect of long term exposure on interdiffusion should be evaluated in these claddings.

Figures 22 (a) shows the microhardness profiles measured within the nickel cladding and $800 \mathrm{H}$ substrate shown in figure 20 (a) and figure 22 (b) shows the measured microhardness profiles within the nickel cladding and 617 substrate shown in figure 20 (b). Note that the microhardness values of the cladding deposited on $800 \mathrm{H}$ are greater than that of the substrate with values ranging from $230 \mathrm{Hv}$ to $320 \mathrm{Hv}$ compared to the substrate value of $\sim 165 \mathrm{Hv}$. The microhardness values within the nickel cladding deposited on alloy 617 substrate are in the range of 230-270 $\mathrm{Hv}$ and comparable to that of the 617 substrate $(\sim 220 \mathrm{Hv})$. The effect of processing conditions on determining the residual stresses and microhardness values need to be addressed in follow-on studies.
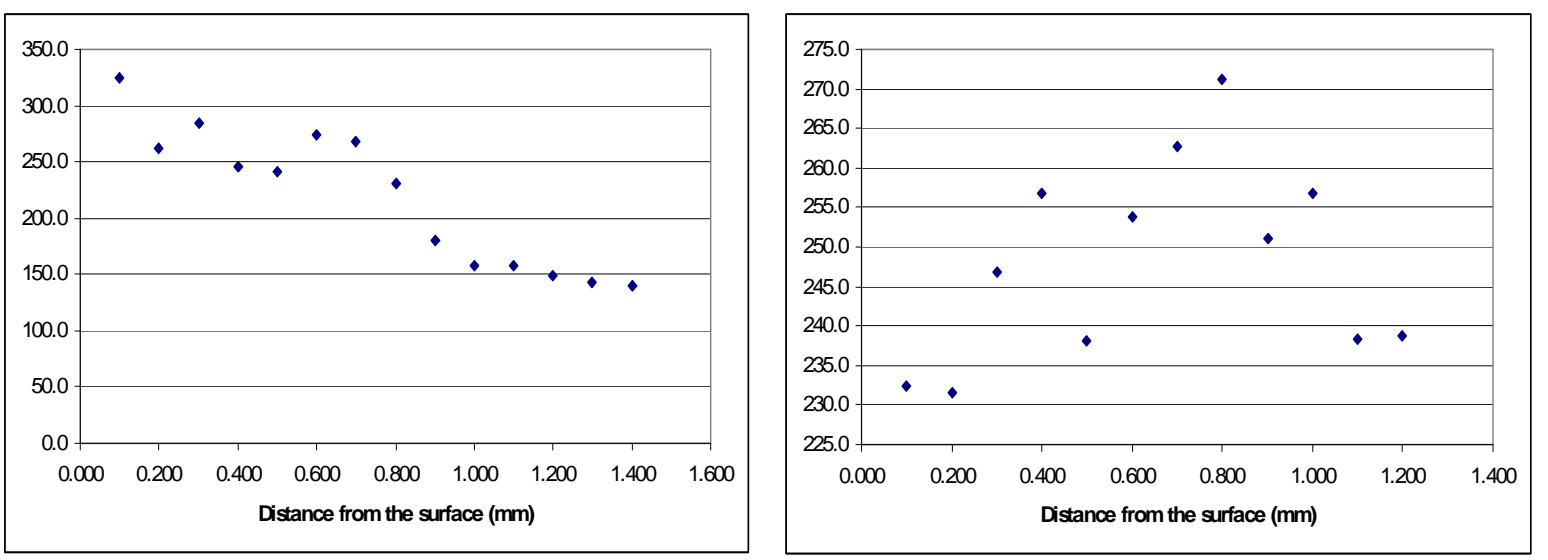

Fig 22. (a) Measured microhardness profile within the Ni cladding and $800 \mathrm{H}$ substrate shown in figure 20 (a). (b) Measured microhardness profile within the Ni cladding and 617 substrate shown in figure 20 (b). 


\section{WELDING OF NICKEL-CLAD NICKEL-BASED ALLOYS}

A cursory literature review indicates there is very little published information about welding or weld performance issues related to welding of nickel-coated nickel-based alloys. Based on a general understanding of welding, one can imagine there are two types of concerns for this situation. The first is the effect of incorporating any nickel cladding into a weld deposit made in a nickel-based alloy or into base metal heat-affected zones. The second type of concern is whether nickel cladding integrity can be maintained after welding operations.

\subsection{CHEMICAL COMPOSITION EFFECTS}

Many nickel-based alloys contain high amounts of alloying elements added to promote hightemperature strength, oxidation resistance, and corrosion resistance. Alloying elements commonly found in nickel-based alloys include chromium, cobalt, molybdenum, niobium, titanium, and tungsten. Other alloy additions, such as magnesium and manganese, help to control impurity elements such as sulfur. Still others, such as boron and zirconium, are added in controlled amounts to promote grain boundary strengthening. While each addition may have a specific role in developing or maintaining the desired properties of an alloy, many of them are implicated in weldability problems. In addition, the contribution that many elements make to cracking issues is sometimes conflicted, being positive, negative, or neutral, depending on factors such as base metal grain size, heat treatment, chemical composition within the normal range, or the type of weldability behavior being tested. Table 9 summarizes early observations about the effects of individual elements on the weldability of nickel-based alloys. It shows that many additions that are desirable for developing good base metal properties have either a variable or a harmful effect on weldability.

Table 11. Effects of some commonly present elements on the weldability of nickel alloys.

\begin{tabular}{cccc}
\hline Beneficial & $\begin{array}{c}\text { No major } \\
\text { effect }\end{array}$ & Variable & Harmful \\
\hline $\mathrm{Nb}$ & $\mathrm{Mn}$ & $\mathrm{Al}$ & $\mathrm{Pb}$ \\
$\mathrm{Mg}$ & $\mathrm{Cu}$ & $\mathrm{Ti}$ & $\mathrm{S}$ \\
& $\mathrm{Cr}$ & $\mathrm{C}$ & $\mathrm{P}$ \\
& $\mathrm{Fe}$ & $\mathrm{Mo}$ & $\mathrm{Zr}$ \\
& $\mathrm{Co}$ & $\mathrm{Si}$ & $\mathrm{B}$ \\
\hline
\end{tabular}

The uncertainties about the effects of individual elements may stem from differences in their behaviors during solidification as compared with their influence on wrought base metal. Nickel-based alloys conform to the same basic characteristics associated with solidification cracking in other alloy systems. An alloy with a relatively large freezing range $\left(\mathrm{T}_{\text {liquidus }}-\mathrm{T}_{\text {solidus }}\right)$ is generally less resistant to solidification cracking than one with a smaller freezing range because there will be a wider temperature range (or a longer time during the solidification process) over which contraction stresses may act to open cracks at liquid-solid interfaces. A related contributing factor is that chemical elements that strongly partition to the liquid phase during solidification and strongly depress melting temperature tend to promote solidification cracking. Additionally, elements that reduce the surface energy of the liquid phase promote its spreading along cell, dendrite, and grain boundaries and thus increase the probability that small amounts of liquid will initiate cracking.

The amount of nickel from a cladding incorporated into a nickel-based weld deposit will depend on several factors related to dimensions and welding parameters. Assuming that full-penetration welds are made, claddings that are thicker than the underlying base metal will result in a weld deposit of 
high nickel concentration relative to that of the base metal. Adding nickel to a nickel-based alloy will tend to increase its melting temperature and decrease its freezing range. Because of this, the added nickel would not be expected to increase the tendency of the base metal to crack during solidification. Concerns about the added nickel will diminish proportionately as the thickness of the cladding becomes a smaller fraction of the combined thickness of the cladding and the base metal.

Solid-state diffusion could also modify the compositions of both claddings and base metals in basemetal heat-affected zones. Generally, heat-affected zones will experience temperatures high enough to permit significant solid-state diffusion for only very short times. From this, it seems reasonable to expect that local properties in heat-affected zones will not be significantly modified by welding operations.

\section{Cladding integrity effects}

Maintaining cladding integrity after any welding operations is an important concern. Clearly, anywhere the base metal is melted, the nickel cladding will be incorporated into the resulting weld deposit. A high-nickel external surface would require either recladding or making the exposed weld beads of high-nickel alloy. Welding electrodes that approach chemical composition of $99 \% \mathrm{Ni}$ are commercially available.

The integrity of claddings in heat-affected zones will depend on such factors as cladding composition, thickness, and original adherence as well as welding parameters and the welding process. The thermal expansion behavior of nickel claddings should be similar to that of nickel-based alloys and should minimize or eliminate buckling failures due to local heating. Because nickel-based alloys typically have lower melting temperatures than pure nickel, concerns about local loss of integrity due to preferential melting should be minimized.

\subsection{REMARKS}

Clearly, this assessment is not exhaustive. Issues related to both chemistry modifications and cladding integrity will depend on numerous factors, including but not limited to the following:

- actual chemical compositions of claddings and base metals,

- the relative thicknesses of claddings and base metals,

- intrinsic adhesion of the cladding to the base metal,

- intrinsic strength and ductility of the nickel cladding,

- the welding process,

- whether or not filler metal is used for welding,

- welding parameters, and

- sensitivity of the exposed nickel to low concentrations of alloying elements. 


\section{ON THE USE OF CLAD HIGH STRENGTH NI-BASED ALLOYS IN FHR}

Structural material for containment of liquid fluoride salts are chosen based on consideration of the reduction-oxidation (redox) potentials of the component elements of the material with respect to components of the salt. The standard free energies of formation per gram atom of fluorine are evaluated for the potential elemental components of the structural material versus that of the fluoride salt at the temperatures of interest. The intent is to have the components of the liquid fluoride salt be more stable than fluoride compounds that could form with the components of the structural material, and so have a non-reactive system. As shown in Figure 23, nickel fluoride is much less stable that the fluorides of lithium and beryllium and hence will not form in FLiBe. As a result, Ni-base alloys are the material of choice for use in liquid fluoride salts. Other alloying elements are then added to the composition to increase the mechanical properties and provide resistance to oxidation in air or other environments. However, fluorides of these additional alloying elements tend to be closer in thermodynamically stability to the components of $\mathrm{FLiBe}$, see for example fluorides of $\mathrm{Al}$ and $\mathrm{Ti}$, and can be more readily partitioned into the fluoride salts. A pure nickel layer on the surface of a high strength Ni-based alloy allows of use of the latter material at high temperature in liquid fluoride salts until the interdiffusion of the alloying elements transports the elements to the coating/salt interface at which time they partition into solution. Hence, at a minimum, nickel coated high strength alloys will allow for short term evaluation of fluoride salt heat transfer systems, and if suitable diffusion barriers can be developed, will allow for longer term use of these materials. Results on the nickel cladding of surface layers shows that the composition of the surface layer can vary from relatively pure nickel to nickel mixed with various elements from the matrix. based on the type of process used. The effect of these elements on the resistance to liquid salt attack should be evaluated in future work.

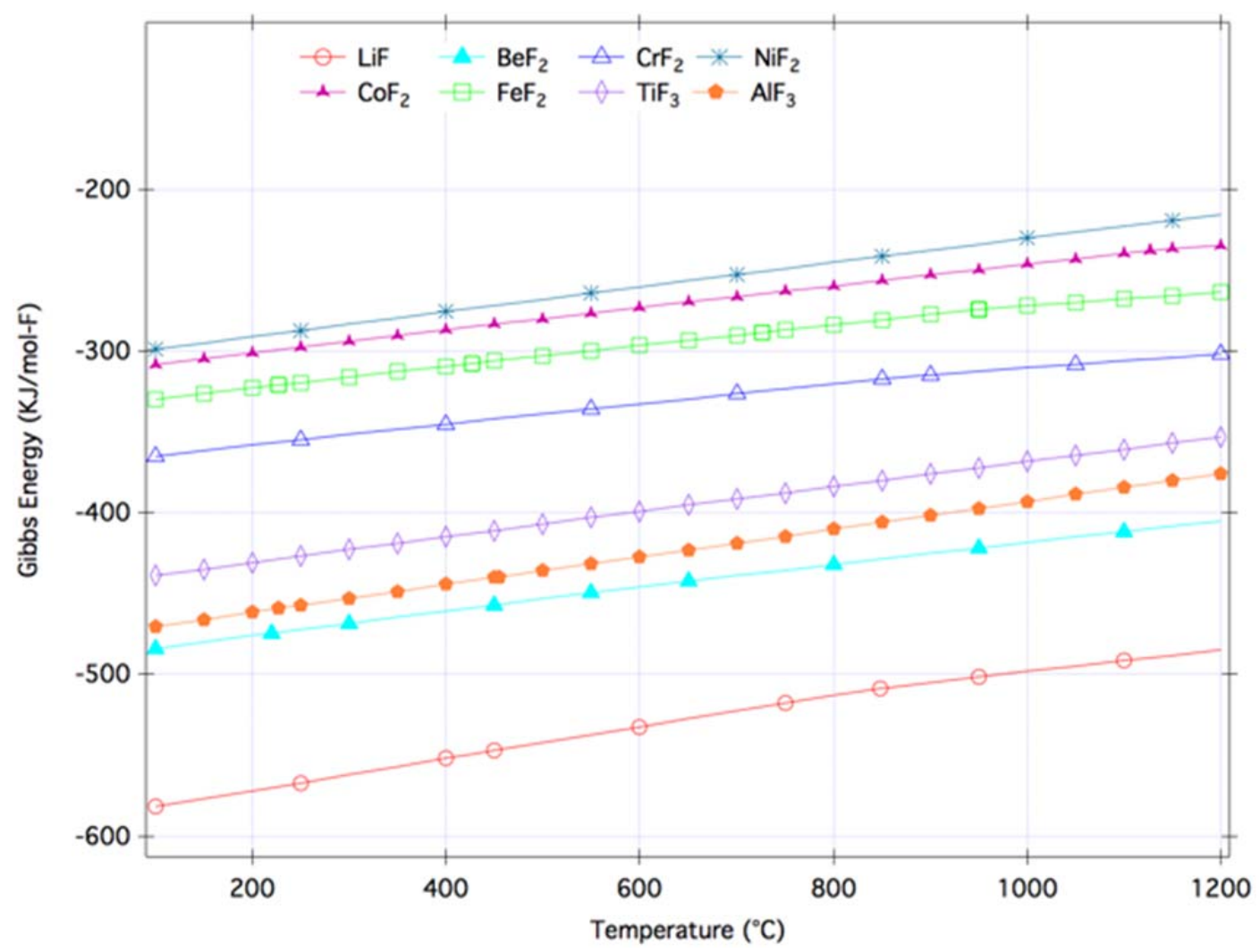

Fig 23. Relative stability of fluorides of typical elements in high strength nickel-based alloys compared to those of fluorides of FLiBe, a salt of interest. 



\section{SUMMARY AND FUTURE WORK}

This report identified the key property requirements of the claddings that would be required for long term service in contact with liquid salt at high temperatures. It provided an overview of several candidate cladding technologies that could potentially be used for cladding nickel-based corrosion protection layers onto high-temperature structural alloys. From the available techniques, two cladding technologies were selected for initial evaluation. The first technique was a line-of-sight method that would be useful for cladding large structures such as vessel interiors or large piping. The line-of-sight method used was a laser-based surface cladding technique in which a high-purity nickel powder mixed into a polymer binder was first sprayed onto the surface, baked, and then rapidly melted using a high-power laser. The second technique was a non-line-of-sight cladding technique- a vapor phase technique based on the nickel-carbonyl process that is suitable for cladding inaccessible surfaces such as the interior surfaces of heat exchangers.

Nickel claddings were prepared on Alloy 617 and Alloy $800 \mathrm{H}$ substrates using the laser-based cladding process and the nickel-carbonyl based MOCVD process. In general, the quality of laserbased claddings was acceptable with occasional presence of few voids, pinholes, and cracks. These were regions in which the coatings had spalled; it is anticipated that optimization of the process would minimize these spalled regions. In addition, good adhesion along with good mixing was present at the interface between the cladding and the substrate. A portion of the substrate from the near-surface region was observed to have melted and intermixed with the cladding material with the size of this region increasing laser power. Alloying elements from the substrate were identified within the cladding layer with their concentration increasing with increase in laser power. In general, the composition gradients were less prominent when the laser claddings were processed at larger powers. Thus, it can be concluded that the laser processing can be successfully used to modify the surface composition of Alloy 617 and Alloy $800 \mathrm{H}$ with appropriate selection of process parameters.

Relatively thick claddings were processed using the MOCVD process. These claddings were of good quality with no pinholes or cracks. In contrast to the laser-based cladding process, sharp interfaces were observed between the cladding and substrate with little or no intermixing. Hence the composition of the nickel cladding layers was essentially pure nickel with little or no matrix elements present within the cladding layer. An intermediate oxide layer was found to be present between the substrate and cladding layers due to initial oxidation of the substrate and could potentially affect the adhesion and interdiffusion between the substrate and the cladding. Results from microhardness tests on the cladding and the near-substrate region in the matrix show that the cladding layer was softer than the matrix.

A cursory literature review indicated there is very little published information about welding or weld performance issues related to welding of nickel-coated nickel-based alloys. Based on a general understanding of welding, one can imagine there are two types of concerns for this situation. The first is the effect of incorporating any nickel cladding into a weld deposit made in a nickel-based alloy or into base metal heat-affected zones. The second type of concern is whether nickel cladding integrity can be maintained after welding operations. These issues have to be addressed to understand the fabricability of FHR components using clad nickel-based alloys.

Several areas of future work were identified on the basis of the current work: 
1. Evaluation of liquid salt resistance of claddings is essential to understand the effect of cladding characteristics on the salt resistance and in particular, the long term resistance characteristics.

2. Optimization of the laser-based cladding process would be required to obtain desired combination of properties- composition, microstructure, adhesion, hardness.

3. Diffusion barriers have to be developed for sustained, long-term operation of the clad material at high temperatures in a liquid-salt environment.

4. Processes to clean the surfaces of substrates have to be developed to ensure that chemical vapor deposited claddings have good adhesion with the substrate.

5. A detailed evaluation must be performed on techniques suitable for welding clad nickel-based alloys and properties of the welded materials should be evaluated. 


\section{ACKNOWLEDGEMENTS}

The authors would like to acknowledge

Kevin Harper for help with laser processing,

David Harper for coordination of the tasks in the materials processing laboratory,

Adam Willoughby for preparation of test specimens,

Jackie Mayotte for optical metallography and hardness measurements,

Rita Ayers for her help with the formatting and typing of the report, and

Dr. Steve Pawell, Dr. Glenn Romonaski, and Dr. Bill Peter for their review of the report. 



\section{REFERENCES}

1. D. F. Williams, L. M. Toth, and K. T. Clarno, Assessment of Candidate Molten Salt Coolants for the Advanced High Temperature Reactor (AHTR), ORNL/TM-2006/12, Oak Ridge National Laboratory, Oak Ridge, Tenn., March 2006.

2. D. E. Holcomb, S. M. Cetiner, G. F. Flanagan, F. J. Peretz, and G. L. Yoder, Jr., An Analysis of Testing Requirements for Fluoride Salt-Cooled High Temperature Reactor Components, ORNL/TM-2009/297, Oak Ridge National Laboratory, Oak Ridge, Tenn., November 2009.

3. D. E. Holcomb and S. M. Cetiner, An Overview of Liquid-Fluoride-Salt Heat Transport Systems, ORNL/TM-2010/156, Oak Ridge National Laboratory, Oak Ridge, Tenn., September 2010.

4. L. J. Koch, H. O. Monson, W. R. Simmons, M. Levenson, F. Verber, E. Hutter, R. A. Jaross, T. R. Spalding, J. R. Simanton, and A. Lovoff, "Construction Design of EBR-II: An Integrated Unmoderated Nuclear Power Plant," Proc. Second United Nations International Conference on the Peaceful Uses of Atomic Energy," Geneva, Switzerland, June 1958.

5. D. F. Wilson, Effects of Materials Testing Requirements and Planning for Implementation of Initial Test Program for Liquid Salt Intermediate Loops, ORNL/GEN4/LTR-6-029, Oak Ridge National Laboratory, Oak Ridge, Tenn., September 2006.

6. G. A. Di Bari, "Nickel Plating," in ASM Handbook (ASM International, 1994), 5: 201-212.

7. T. Mooney, "Electroplated Coatings," in ASM Handbook (ASM International, 2003), 13A: 772-785.

8. D. W. Baudrand, "Electroless Nickel Plating," in ASM Handbook (ASM International, 1994), 5: 290-310.

9. D. M. Mattox, "Vacuum Deposition, Reactive Evaporation, and Gas Evaporation," in ASM Handbook (ASM International, 1994), 5: 556-572.

10. "CVD and PVD Coatings," in ASM Handbook (ASM International, 2003), 13A: 759-762.

11. S. L. Rohde, "Sputter Deposition," in ASM Handbook (ASM International, 1994), 5: 573-581.

12. H. O. Pierson, "Chemical Vapor Deposition of Nonsemiconductor Materials," in ASM Handbook (ASM International, 1994) 5: 510-516.

13. R. C. Tucker, Jr, "Thermal Spray Coatings," in ASM Handbook (ASM International, 1994), 5: 497-509.

14. K. P. Cooper, "Laser Surface Processing," in ASM Handbook (ASM International, 1992), 18: 861-872.

15. R. Srinivasan and C. S. Hartley, "Coextrusion," in ASM Handbook (ASM International, 2005), 14A: $505-51$. 